NBER WORKING PAPER SERIES

\title{
A MODEL OF THE SAFE ASSET MECHANISM (SAM): SAFETY TRAPS AND ECONOMIC POLICY
}

\author{
Ricardo J. Caballero \\ Emmanuel Farhi \\ Working Paper 18737 \\ http://www.nber.org/papers/w18737
NATIONAL BUREAU OF ECONOMIC RESEARCH
1050 Massachusetts Avenue
Cambridge, MA 02138
January 2013

For useful comments, we thank Daron Acemoglu, Oliver Hart, Gary Gorton, Bengt Holmstrom, Narayana Kocherlakota, Guillermo Ordonez, Ricardo Reis, Andrei Shleifer, Alp Simsek, Jeremy Stein, Kevin Stiroh, and Ivan Werning. The views expressed herein are those of the authors and do not necessarily reflect the views of the National Bureau of Economic Research.

NBER working papers are circulated for discussion and comment purposes. They have not been peerreviewed or been subject to the review by the NBER Board of Directors that accompanies official NBER publications.

(C) 2013 by Ricardo J. Caballero and Emmanuel Farhi. All rights reserved. Short sections of text, not to exceed two paragraphs, may be quoted without explicit permission provided that full credit, including (C) notice, is given to the source. 
A Model of the Safe Asset Mechanism (SAM): Safety Traps and Economic Policy

Ricardo J. Caballero and Emmanuel Farhi

NBER Working Paper No. 18737

January 2013, Revised August 2013

JEL No. E32,E4,E5,E52,E62,E63,F3,F33,F41,G01,G1,G28

\begin{abstract}
The global economy has a chronic shortage of safe assets which lies behind many recent macroeconomic imbalances. This paper provides a simple model of the Safe Asset Mechanism (SAM), its recessionary safety traps, and its policy antidotes. Safety traps share many common features with conventional liquidity traps, but also exhibit important differences, in particular with respect to their reaction to policy packages. In general, policy-puts (such as QE1, LTRO, fiscal policy, etc.) that support future bad states of the economy play a central role in the SAM environment, while policy-calls that support the good states of the recovery (e.g., some aspects of forward guidance) are less powerful. Public debt plays a central role in SAM as long as the government has spare fiscal capacity to back safe asset production.
\end{abstract}

\author{
Ricardo J. Caballero \\ MIT \\ Department of Economics \\ Room E52-373a \\ Cambridge, MA 02142-1347 \\ and NBER \\ caball@mit.edu \\ Emmanuel Farhi \\ Harvard University \\ Department of Economics \\ Littauer Center \\ Cambridge, MA 02138 \\ and NBER \\ efarhi@harvard.edu
}




\section{Introduction}

One of the main structural features of the global economy in recent years is the apparent shortage of safe assets (see, e.g., Caballero 2010 and references therein). This deficit provided the macroeconomic force for the financial engineering behind the subprime crisis, is a paramount factor in determining the spike in funding costs when European economies switch from the core to the periphery, and has put new constraints on the effectiveness of monetary and fiscal policy. However, while much has been written about the potential importance of this scarcity, there is little formal understanding of how this shortage influences the macroeconomy and of what is the appropriate policy response. This paper's main contribution is to provide a simple model of the Safe Asset Mechanism (SAM) and its policy antidotes.

The central problem in SAM is one of "excess" demand for safe assets. This financial market problem spreads to the real economy through multiple channels. On the aggregate supply side, corporations (including the financial sector) trade less potential production for safer revenue. On the aggregate demand side (the side we highlight), SAM is characterized by the strong downward pressure it puts on safe interest rates. If there is a limit on how much these rates can drop, a safety-trap emerges, akin to the Keynesian liquidity trap. In this context, a recession restores equilibrium in asset markets by reducing the wealth of safe-savers and hence their asset demand. Overall, SAM provides a parsimonious account for symptoms also found in environments experiencing the combined effect of a credit crunch and a liquidity trap.

In SAM, as in the more conventional credit crunch mechanism, a wedge develops between the risky and riskless rate. However, in SAM, it is the safe rate drop that drives this wedge, and it is this rate that is the main sign of trouble. Although in practice both mechanisms are likely to operate in conjunction, it is important to establish their differences as they do not respond equally to different policy packages.

Public debt plays a central role in SAM. The central concept here is that of fiscal capacity: How much public debt can the government credibly pledge to honor, should a major macroeconomic shock take place in the future? The key issue is that the government owns a disproportionate share of the capacity to create safe assets, and the private sector owns too many risky assets. As long as the government has spare fiscal capacity to back safe asset production, the government can increase the supply of safe assets by issuing public debt. This reduces the root imbalance in the economy. We use this framework to analyze the impact of different policy options implemented recently in the U.S. and other developed 
economies. In general, policy-puts (such as QE1 in the U.S., LTRO in Europe, fiscal policy, etc.) that support future bad states of the economy play a central role in this environment, while policy-calls that support the good states of the recovery (e.g., some aspects of forward guidance) are less powerful.

Swapping risky private assets for safe public debt, which with some abuse of terminology we refer to as Quantitative Easing (QE) type policies, and which encompass the recent QE1 in the U.S. and LTRO in Europe as well as many other lender of last resort central bank interventions, have positive effects on spreads and output. In contrast, swapping short-run public debt for long-run public debt, which we refer to as Operation Twist (OT), and which encompass the recent QE2 and QE3 in the U.S., can be counterproductive. The reason for the latter is that long term public debt, by being a "bearish" asset that can be used to hedge risky private assets, has a safe asset multiplier effect that short term public debt lacks. That is, long term public debt is not only a safe asset in itself, but also makes risky private assets safer through portfolio effects. ${ }^{1}$

Fiscal policy is the goods-markets side of public debt policy. Once fiscal capacity runs out, that is, once the government's ability to create safe assets runs out, short term fiscal policy becomes less effective. In contrast, credible long run fiscal consolidation becomes powerful, as it relaxes the fiscal capacity constraint and allows the government to sustain higher debt, thereby increasing the supply of assets and boosting the economy. While the efficacy of long run fiscal consolidation relies on its impact on the ability of the government to increase the supply of safe assets, it is also possible for the government to successfully stimulate the economy by reducing the demand for safe assets. Indeed, the government can stimulate the economy by simply taxing away the wealth of the agents with the highest demand for safe assets, and either rebating the proceeds to agents with a lower demand for safe assets, or using them to increase government spending.

We also discuss the role of monetary policy commitments in a safety trap, and show that they alleviate the shortage only if they support future bad states of nature (a policyput). The reason is, again, that in a SAM environment the main problem is the very low equilibrium safe rate, not the large risk-spread. Commitments to low interest rates in future good states (a policy call) - the way forward guidance type policies are usually discussedare ineffective precisely because they attempt risky assets revaluation rather than the safe

\footnotetext{
${ }^{1}$ From SAM's perspective, an interesting (and conceptually correct) argument often made in favor of OT is that the policy itself enhances the bearish nature of long term debt by tightening the negative correlation between long term debt and the state of the economy. Whether this effect dominates the one we highlight in the main text is uncertain at this time.
} 
asset expansion that SAM requires. By contrast, commitments to low interest rates in future bad states are effective precisely because they increase the value of safe assets. However, it is natural to question whether monetary authorities would have the ability to lower interest rates in future bad states (they might coincide with another safety or liquidity trap). We are therefore left with a somewhat skeptical view of forward guidance policies in a SAM environment. ${ }^{2}$

The SAM environment resembles in many respects the Keynesian liquidity trap environment, but it also has important differences with it. We devote a section to highlight these differences. For example, we show that QE type policies are more powerful in SAM than in liquidity trap environments. In contrast, fiscal policy and forward guidance are more effective in the latter than in SAM.

Related literature. Our paper is related to several strands of literature. First and most closely related is the literature that identifies the shortage of safe assets as key macroeconomic fact (see e.g. Caballero 2006 and 2010, Caballero and Krishnamurthy 2009, Bernanke et al 2011, Barclay's 2012). Our paper provides a model that captures many of the key insights in that literature and that allows us to study the main macroeconomic policy implications of this environment more precisely.

Second, the literature on aggregate liquidity (see e.g. Woodford 1990 and Holmström and Tirole 1998) analyzes the shortage of liquidity (stores of value). It has emphasized the role of governments in providing (possibly contingent) stores of value that cannot be created by the private sector. Our paper shares the idea that liquidity shortages are important macroeconomic phenomena, and that the government has a special role in alleviating them. However, it shifts the focus to a very specific form of liquidity - safe assets - and works out its distinct and unique consequences.

Third, there is a literature that documents significant deviations from the predictions of standard asset-pricing models-patterns which can be thought of as reflecting moneylike convenience services - in the pricing of Treasury securities generally, and in the pricing of short-term T-bills more specifically (Krishnamurthy and Vissing-Jorgensen 2011, 2012, Greenwood and Vayanos 2010, Duffee 1996, Gurkaynak, Sack and Wright 2006, Bansal and Coleman 1996). Our model offers a distinct interpretation of these stylized facts, where the "specialness" of public debt is its safety during bad states of the economy.

\footnotetext{
${ }^{2}$ Of course in practice SAM is only one of the many ills that affect an economy in distress. Our policy effectiveness claims relate to the SAM dimension of the problem only.
} 
Fourth, there is an emerging literature which emphasizes how the aforementioned premium creates incentives for private agents to rely heavily on short-term debt, even when this creates systemic instabilities (Gorton and Metrick 2010, 2012, Gorton 2010, Stein 2012, Woodford 2012, Gennaioli, Shleifer and Vishny 2012). Greenwood, Hanson and Stein (2012) consider the role of the government in increasing the supply of short-term debt and affecting the premium. Gorton and Ordonez (2013) also consider this question but in the context of a model with (asymmetric) information acquisition about collateral where the key characteristic of public debt that drives its premium is its information insensitivity. Our model also considers how this premium affects private agent's balance sheets, but it offers distinct mechanisms for its source, and on how it affects the economy and macroeconomic policy.

Fifth, there is the literature on liquidity traps (see e.g. Keynes 1936, Krugman 1998, Eggertsson and Woodford 2003, Christiano, Eichenbaum and Rebelo 2011, Correia, Farhi, Nicolini and Teles 2012, Werning 2012). This literature emphasizes that the binding zero lower bound on nominal interest rates presents a challenge for macroeconomic stabilization. In most models of the liquidity trap, the corresponding asset shortage arises from an exogenous increase in the propensity to save (a discount factor shock). Some recent models (see e.g. Guerrieri and Lorenzoni 2011, and Eggertsson and Krugman 2012) provide deeper microfoundations and emphasize the role of tightened borrowing constraints in economies with heterogeneous agents (borrowers and savers). Our model of a safety trap shares elements of the Keynesian liquidity trap story. However, in our model the key interest rate is the safe interest rate, and the root cause of safety traps is an acute safe asset shortage. This crucial distinction has important policy implications.

Finally, our paper relates to an extensive literature, both policy and academic, on fiscal sustainability and the consequences of current and future fiscal adjustments (see, e.g., Giavazzi and Pagano 1990, 1996, Alesina and Ardagna 1998, IMF 1996, Guihard et al 2007). Our paper revisits some of the policy questions in this literature but highlights the government's capacity to create safe assets at the margin, as the key concept to determine the potential effectiveness of further fiscal expansions as well as the benefits of future fiscal consolidations. $^{3}$

\footnotetext{
${ }^{3}$ Our paper is also related to a strand of literature on global imbalances. Caballero, Farhi and Gourinchas $(2008 \mathrm{a}, \mathrm{b})$ developed the idea that global imbalances originated in the superior development of financial markets in developed economies, and in particular the U.S. Global imbalances resulted from an asset imbalance. Although we do not develop the open economy version of our model here, SAM implies a specific channel that lies behind global imbalances: The latter were caused by the funding countries' demand for financial assets in excess of their ability to produce them, but this gap is particularly acute for safe assets since emerging markets have very limited institutional capability to produce them.
} 
The paper is organized as follows. Section 2 describes our basic model and introduces the key mechanism of a safety trap. Section 3 introduces public debt and considers the effects of balance sheet policies (QE and OT) and fiscal policies (redistributive policies, government spending). Section 4 analyzes the role of forward guidance (monetary policy commitments). Section 5 develops a version of a liquidity trap in the context of our model and explains the similarities and differences with a safety trap. Section 6 concludes.

\section{A Model of SAM}

In this section we describe SAM without government intervention. When a shortage of safe assets arises, interest rates need to drop to reduce the return on these assets and hence their demand. However, if there is a lower bound for interest rates, then a safety trap emerges and asset markets are cleared through a recession.

\subsection{Basic Model}

Setup. The basic model has exogenous output. The goal is to characterize demand and supply of safe assets, and their impact on equilibrium returns.

Output is constant, $X$, unless a Poisson shock takes place, in which case it drops to $\mu X<X$ forever. We focus on the period before this shock takes place. The Poisson event happens with hazard $\lambda$, and we simplify the notation by studying the limit as $\lambda \rightarrow 0$.

Population has a perpetual-youth overlapping generations structure with death and birth rates $\theta$. Agents consume only when they die, which yields a simple aggregate consumption function $C_{t}=\theta W_{t}$, where $C_{t}$ and $W_{t}$ represent aggregate consumption and wealth, respectively. Note that equilibrium in goods markets pins down the equilibrium value of aggregate wealth $W_{t}$ at

$$
W=\frac{X}{\theta}
$$

Next, we introduce two key ingredients of the model, one about asset demand, and one about asset supply. On the asset demand side, there are two types of agents in the economy: Neutral and (locally) Knightian. Neutral agents are risk-neutral. Knightian agents are infinitely risk averse (over short time intervals): between $t$ and $t+d t$, when forming their portfolio, they act as if the Poisson shock happens in the next infinitesimal time interval 
with probability one. The fraction of Neutrals in the population is $1-\alpha$. The fraction of Knightians is $\alpha$. We denote the wealth of Neutral and Knightian agents by $W_{t}^{N}$ and $W_{t}^{K}$ with

$$
W_{t}^{N}+W_{t}^{K}=W
$$

On the asset supply side, we assume that a fraction $\delta$ of output $X$ is pledgeable and accrues as the total dividend of Lucas trees (each tree capitalizes a stream of $\delta$ units of goods per period). The rest, $(1-\delta) X$, is distributed to newborns. The total value of assets before the Poisson shock is $V$, and from financial market equilibrium we have:

$$
V=W=\frac{X}{\theta}
$$

We assume that only a fraction $\rho$ of these assets can be tranched to split the risky and riskless component of returns. We denote by $V^{\mu}$ and $V^{r}$ the supply of safe and risky assets with

$$
V=V^{\mu}+V^{r}
$$

A safe asset is one whose value does not change when the Poisson event takes place. Thus, we can find $V^{\mu}$ by solving backwards and noting that by construction a fraction $\rho$ of the total value of assets after an adverse Poisson shock is safe:

$$
V^{\mu}=\rho \mu \frac{X}{\theta}
$$

Risky assets (before the Poisson event) are worth the residual $V-V^{\mu}$ :

$$
V^{r}=(1-\rho \mu) \frac{X}{\theta}
$$

Since Knightian agents only hold safe assets, their wealth holdings, $W_{t}^{K}$, must satisfy:

$$
W_{t}^{K} \leq V^{\mu}
$$

Let $r, r^{K}$, and $\delta^{\mu}$ denote the (ex-ante) rate of return on risky assets, the rate of return on safe assets, and the dividend paid by safe assets, respectively. Then equilibrium is characterized by the following equations:

$$
r^{K} V^{\mu}=\delta^{\mu} X
$$




$$
\begin{gathered}
r V^{r}=\left(\delta-\delta^{\mu}\right) X, \\
\dot{W}_{t}^{K}=-\theta W_{t}^{K}+\alpha(1-\delta) X+r^{K} W_{t}^{K}, \\
\dot{W}_{t}^{N}=-\theta W_{t}^{N}+(1-\alpha)(1-\delta) X+r W_{t}^{N}, \\
W_{t}^{K}+W_{t}^{N}=V^{\mu}+V^{r} .
\end{gathered}
$$

Two regimes. There are two regimes, depending on whether the constraint $W_{t}^{K} \leq V^{\mu}$ is slack (unconstrained regime) or binding (constrained regime).

In the unconstrained regime, since Neutrals are the marginal holders of safe assets, safe and risky rates must be equal. A few steps of algebra show that in this case:

$$
\begin{gathered}
\delta^{\mu}=\delta \rho \mu, \\
r=r^{K}=\delta \theta .
\end{gathered}
$$

The interesting case for us is the constrained regime, which captures the safe asset shortage environment. In it, Knightians gobble up all safe assets and wish they had more, so that:

$$
W^{K}=V^{\mu}=\rho \mu \frac{X}{\theta} .
$$

It is easy to verify that this regime holds (after possibly a transitional period) as long as $\alpha>\rho \mu{ }^{4}$ The latter is the safe asset shortage condition, which we shall assume holds henceforth. In this case we have:

$$
\begin{gathered}
\delta^{\mu}=\delta \rho \mu-(\alpha-\rho \mu)(1-\delta)<\delta \rho \mu, \\
r^{K}=\delta \theta-(1-\delta) \theta \frac{\alpha-\rho \mu}{\rho \mu}<\delta \theta,
\end{gathered}
$$

\footnotetext{
${ }^{4} \mathrm{~A}$ delicate issue is the initial value of risky assets. It is possible for the value of risky assets (and hence total assets) to jump at date 0 and so we distinguish $0^{-}$and $0^{+}$. We denote by $\beta_{0_{-}}^{\mu}$ and $\beta_{0_{-}}^{r}$ the fraction of safe assets and risky assets initially owned by Knightians. The initial budget constrained of Knightians implies

$$
\beta_{0_{-}}^{r} V_{0_{-}}^{r} \leq\left(1-\beta_{0_{-}}^{\mu}\right) \rho \mu \frac{X}{\theta},
$$
}

and the absence of arbitrage for Neutrals requires that

$$
V_{0_{-}}^{r} \leq V_{0^{+}}^{r}=(1-\rho \mu) \frac{X}{\theta} .
$$




$$
r=\delta \theta+(1-\delta) \theta \frac{\alpha-\rho \mu}{1-\rho \mu}>\delta \theta
$$

It follows that in this region there is a safety premium

$$
r-r^{K}=(1-\delta) \theta \frac{\alpha-\rho \mu}{\rho \mu(1-\rho \mu)}>0
$$

The supply of safe assets is determined by the severity of the potential shock $(\mu)$ and the ability of the economy to create safe assets $(\rho)$. In fact $\rho$ and $\mu$ enter the equilibrium equations only through the sufficient statistic $\rho \mu$. Similarly, the demand for safe assets is summarized by the fraction of Knightians $(\alpha)$. Together, these sufficient statistics determine whether we are in the unconstrained regime $(\alpha \leq \rho \mu)$ or in the constrained regime $(\alpha>\rho \mu)$.

Discussion. Our model features two forms of market incompleteness. The first one is tied to our overlapping generations structure. As a result, our environment is non-Ricardian and asset supply $(\delta)$ matters. The second market incompleteness is that only a fraction of trees $(\rho)$ can be tranched. ${ }^{5}$ Tranching is desirable because it decomposes an asset into a safe tranche which can be sold to Knightian agents and a risky tranche that can only be sold to Neutral agents. Because agents cannot tranch assets at will, Modigliani-Miller fails in the sense that in the constrained regime the value $v^{t}$ of a unit of tranched tree is higher than that of an untranched tree $v^{n t}$. This gap widens as the safe asset shortage $(\alpha-\rho \mu)$ worsens:

$$
v^{t}-v^{n t}=\frac{1}{\theta} \frac{\alpha-\rho \mu}{\rho} \frac{1-\delta}{1-\rho \mu-(1-\alpha)(1-\delta)}
$$

Up to now we have assumed production is exogenous and focused on the spread side of SAM. But in reality production and demand decisions are also strongly influenced by risk perceptions and the corresponding spreads. In the appendix (Section 7.1.2) we focus on a supply side mechanism, while in the next section we turn to a demand mechanism.

\subsection{Safety Trap}

As the potential shock becomes more extreme (i.e., as $\mu$ drops), or the economy's ability to create safe assets is more impaired ( $\rho$ drops), the supply of safe assets shrinks ( $\rho \mu$ drops). Equilibrium is restored by a decline in $r^{K}$ which lowers demand for safe assets. But what

\footnotetext{
${ }^{5} \mathrm{~A}$ simple extension of our model allows us to think about pooling in addition to tranching. We refer the reader to the appendix for this extension.
} 
if there is a limit $\underline{r}^{K}$ on how much $r^{K}$ can drop? In this section we address this issue and show how an excess demand for safe assets can trigger a recession.

We develop our argument in two steps. In Section 2.2.1, we use a simple disequilibrium framework to isolate the mechanics of the interaction between an aggregate demand determined output and a lower bound on safe rates. In Section 2.2.2 (which can be skipped if persuaded by the first step), we develop a New Keynesian model with a Cash In Advance constraint that provides an example of the safety trap mechanism we describe in the first step. In that model, the lower bound $\underline{r}^{K}$ is equal to zero and arises from the possibility of arbitraging between money and other safe assets. ${ }^{6}$

\subsubsection{The Mechanics of a Safety Trap}

The extra restriction $r^{K} \geq \underline{r}^{K}$ forces us to consider disequilibrium in some other market, which we assume to be the goods market as this connects our discussion with standard Keynesian demand arguments. We introduce a distinction between potential output $X$ and actual output $\xi X$. When $\xi<1$, output is below potential. We reinterpret endowments of goods $(1-\delta) X$ and dividends $\delta X$ as endowments of a non-traded input (say labor) that can be converted into output one-to-one. When $\xi<1$, less of this input is converted into output. This modelling strategy essentially sidesteps the labor market. In every period, there is a goods market and an asset market. Dying old agents supply assets and demand goods. Survivors and newborns demand assets and supply goods.

Let us work backwards and recall that after the negative Poisson shock hits (which never literally happens in our model since $\lambda \rightarrow 0$ ), uncertainty disappears and so does the safe asset shortage. This means that actual and potential output coincide after the shocks and

\footnotetext{
${ }^{6}$ Our general model allows for a general lower bound $\underline{r}^{K}$ which can potentially be different from zero because we think that the restriction $r^{K} \geq \underline{r}^{K}$ could also be interpreted as a stand-in for other mechanisms than arbitrage with money. Indeed, very low interest rates may be problematic for a variety of reasons, ranging from distributional considerations (e.g., against retirees) to financial markets ones. These considerations could be another potential justification for the lower bound $\underline{r}^{K}$. A possible modelling strategy would be to introduce some discontinuity in Knightians preferences: They cannot survive or suffer a very large utility loss with returns below $\underline{r}^{K}$ (but they still strictly prefer to hold only riskless assets over risky assets when the return on the former is $\underline{r}^{K}$ ). There could also be a discontinuity on the supply side, stemming from institutional and cost constraints on the intermediation sector (e.g., money markets may switch in mass to gambling for resurrection once rates drop to sufficiently low levels). Depending on the exact specification, there would either be no equilibrium with $r^{K}<\underline{r}^{K}$ or only very bad equilibria (from a welfare perspective). Then either the monetary authority could be unable to set a nominal interest rate $i^{K}$ below $\underline{r}^{K}$ or it would choose not to.
} 
therefore the value of safe assets (before the shock) is still given by

$$
V^{\mu}=\rho \mu \frac{X}{\theta}
$$

Note that, mechanically, this "disequilibrium" model is identical to the basic model but with $\rho \mu$ replaced by $\frac{\rho \mu}{\xi}$ and $X$ replaced by $\xi X$. The requirement that $r^{K}=\underline{r}^{K}$ determines the severity of the recession $\xi$ :

$$
\underline{r}^{K}=\delta \theta-(1-\delta) \theta \frac{\alpha-\frac{\rho \mu}{\xi}}{\frac{\rho \mu}{\xi}},
$$

yielding

$$
\xi=\frac{\rho \mu}{\underline{\rho \mu}}<1
$$

where $\rho \mu$ corresponds to the value of these combined parameters for which $\underline{r}^{K}$ is the equilibrium safe interest rate (e.g., when $\left.\underline{r}^{K}=0, \underline{\rho \mu}=\alpha(1-\delta)\right){ }^{7}$

Because the safe interest rate $r^{K}$ cannot adjust downwards, there is a recession. This mechanism is akin to that of a liquidity trap. We call it a "safety trap". A recession lowers the absolute demand for safe assets while keeping the absolute supply of safe assets fixed and restores equilibrium. Figure 1 illustrates this mechanism, which we describe next.

The supply of safe assets is given by $V^{\mu}=\rho \mu \frac{X}{\theta}$ and the demand for safe assets is given by $W^{K}=\frac{\alpha(1-\delta) \xi X}{\theta-r^{K}}$. Equilibrium in the safe asset market requires that $W^{K}=V^{\mu}$, i.e.

$$
\frac{\alpha(1-\delta) \xi X}{\theta-r^{K}}=\rho \mu \frac{X}{\theta}
$$

Consider an unexpected (zero ex-ante probability) shock that lowers the supply of safe assets (a reduction in $\rho \mu$ ). The mechanism by which equilibrium in the safe asset market is restored has two parts. The first part immediately reduces Knightian wealth $W^{K}$ to a lower level, consistent with the lower supply for safe assets $\rho \mu \frac{X}{\theta}$. The second part maintains Knightian wealth $W^{K}$ at this lower level.

The first part of the mechanism is as follows. The economy undergoes an immediate wealth adjustment (the wealth of Knightians drops) through a round of trading between

\footnotetext{
${ }^{7}$ The risky interest rate $r$ is increasing in $\xi$, so that the deeper the recession, the lower is $r$ :
}

$$
r=\delta \theta+(1-\delta) \theta \frac{\alpha-\frac{\rho \mu}{\xi}}{1-\frac{\rho \mu}{\xi}} .
$$


Figure 1: Safety trap.

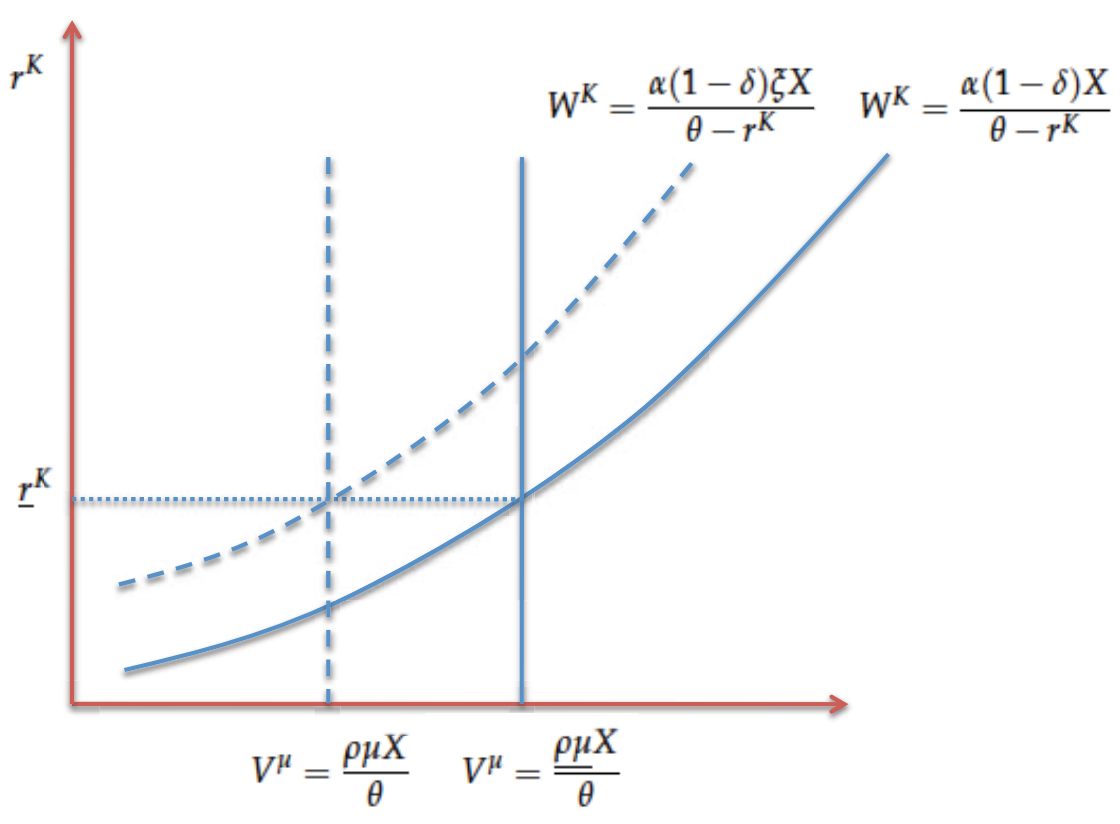

Recession caused by a decrease in the supply of safe assets. The safe asset supply curve shifts left $(\rho \mu<\underline{\rho \mu})$, the endogenous recession shifts the safe asset demand curve left $(\xi<1)$, and the safe interest rate remains unchanged at $\underline{r}^{K}$.

Knightians and Neutrals born in previous periods. At impact, Knightians hold assets that now carry some risk. They react by selling the risky part of their portfolio to Neutrals. This shedding of risky assets catalyzes an instantaneous fire sale whereby the price of risky assets collapses before immediately recovering once risky assets have changed hands. Needless to say, in reality this phase takes time, which we have removed to focus on the phase following the initial turmoil.

The second part of the equilibrating mechanism differs depending on whether the safe interest rate $r^{K}$ is above or at the lower bound $\underline{r}^{K}$. If $r^{K}>\underline{r}^{K}$, then a reduction in the safe interest rate $r^{K}$ takes place. This reduction in the safe interest rate effectively limits the growth of Knightian wealth so that the safe asset market remains in equilibrium. If the safe interest rate is against the lower bound $r^{K}=\underline{r}^{K}$, then this reduction in the safe interest rate cannot take place. With full capacity utilization and $r^{K}=\underline{r}^{K}$, the growth rate of Knightian wealth would be too high and an excess demand for safe assets would develop over time. Instead, a recession takes place (a reduction in $\xi$ ) which reduces the income of Knightians (newborns) and hence the growth of Knightian wealth. 
Note that the recession drags down the whole economy, reducing not only the income of Knightians, but also that of Neutrals (the dividends on risky assets and the income of Neutrals newborns) and hence the wealth of Neutrals. Of course, the flip side of this reduction in Neutral wealth is a reduction in the value of risky assets, which occurs through a reduction in dividends (and despite a decrease in the risky interest rate $r$ ). The reduction in Neutral wealth in turn reduces demand in the goods market, thereby justifying the recession. ${ }^{8}$

A similar logic applies if we raise the share of Knightian agents $\alpha$ instead of reducing $\rho \mu$, in which case the recession factor is

$$
\xi=\frac{\underline{\alpha}}{\alpha}<1 .
$$

This interpretation resembles the paradox of thrift. Combining both, asset supply and demand factors, we have that the severity of the recession is determined by the sufficient statistic $\frac{\rho \mu}{\alpha}$ according to the simple equation:

$$
\xi=\frac{\underline{\alpha}}{\rho \mu} \frac{\rho \mu}{\alpha} .
$$

Although our framework is not designed to discuss normative issues, in practice it seems evident that a recession is a costly mechanism to restore equilibrium in safe asset markets. We turn to policy options later in the paper.

\subsubsection{A New Keynesian Cash-In-Advance Example}

In this section we flesh out an example whose equilibrium exhibits the safety trap feature and mechanics described above. Again, we do it in two steps. The first step consists of making output demand determined and to associate real to nominal safe rates by adding standard New Keynesian features. ${ }^{9}$ The second step adds money and its transaction role,

\footnotetext{
${ }^{8}$ Note that the adjustment in Knightian wealth is the same whether the safe interest rate $r^{K}$ is or is not at the lower bound $\underline{r}^{K}$. What is different is the adjustment in Neutral wealth. In response to a negative shock to the value of safe assets, Neutral wealth ends up at a lower level when the safe interest rate is against the lower bound than when it can freely adjust downwards.

${ }^{9} \mathrm{An}$ alternative would have been to stick to disequilibrium theory. In the language of disequilibrium theory (see e.g. Barro and Grossman 1971, Malinvaud 1977, Benassy 1986, as well as Hall 2011a,b, Kocherlakota 2012, and Korinek and Simsek 2013 for more recent applications), there is excess supply in the goods market and excess demand in the asset market, and in particular an excess demand for safe assets. The gap between the notional and effective supply of goods and demand for assets can be formalized by supplementing the budget constraints of surviving old agents and newborns with quantity constraints (the demand for goods, and the supply of assets). The analysis then characterizes how a disequilibrium in the asset market spills over to a disequilibrium in the goods markets. The advantage of the New Keynesian formulation over a disequilibrium approach is that the economy is always in equilibrium, even if this equilibrium can be
} 
which introduces a lower bound for safe rates and links the use of money as a store of value (as opposed to transaction services) to the severity of the recession.

Demand determined output Let us incorporate the traditional ingredients of New Keynesian economics: imperfect competition, sticky prices and a monetary authority.

In this setting, in every period, non-traded inputs are used to produce differentiated varieties of goods $x_{k}$ indexed by $k \in[0,1]$ where each variety is produced using a different variety of non-traded good also indexed by $k \in[0,1]$. We index trees by $i \in[0, \delta]$, where each tree $i$ yields a dividend of $X$ non traded goods. Similarly, we index newborns by $j \in[\delta, 1]$ where each newborn $j$ is endowed with $X$ non-traded goods. Goods with indices $k \in[0, \delta]$ are produced with the non-traded inputs from the dividends of trees indexed by $k$, and goods with indices $k \in[\delta, 1]$ are produced with the non-traded inputs from the endowments of the newborns indexed by $k$. Each variety is sold by a monopolistic firm. Firms post prices $p_{k}$ in units of the numeraire. These differentiated varieties of goods are valued by consumers according to a standard Dixit-Stiglitz aggregator $\xi X=\left(\int_{0}^{1} x_{k}^{\frac{\sigma-1}{\sigma}} d k\right)^{\frac{\sigma}{\sigma-1}}$, and consumption expenditure is $P \xi X=\int_{0}^{1} p_{k} x_{k} d k$ where the price index is defined as $P=\left(\int_{0}^{1} p_{k}^{1-\sigma} d k\right)^{\frac{1}{1-\sigma}}$. The resulting demand for each variety is given by $x_{k}=\left(\frac{p_{k}}{P}\right)^{-\sigma} \xi X$.

The prices of different varieties are entirely fixed (an extreme form of sticky prices) and equal to each other $p_{k}=P$. Firms accommodate demand at the posted price, and firm profits accrue to the agent owning and supplying the corresponding non-traded input. Without loss of generality, we use the normalization $P=1$. Note that because the prices of all varieties are identical, the demand for all varieties is the same. Output is demand-determined, and as a result, capacity utilization rate $\xi$ is the same for all firms (the recession is economywide) so that $x_{k}=\xi X$ for all $k$.

Finally, a monetary authority sets a safe nominal interest rate $i^{K}$. Because prices are rigid, this determines the real interest rates $r^{K}=i^{K}$. The resulting model yields exactly the same equations as those used in the previous section.

Money, the Zero Lower Bound and the Cashless Limit To justify a zero lower $r^{K} \geq \underline{r}^{K}$ with $\underline{r}^{K}=0$, we introduce money into the model. We then define a cashless limit (see e.g. Woodford 2003) and show that in that limit, the economy converges to our basic inefficient (with output below potential). This is why we choose to adopt it. 
model.

We represent the demand for real money balances for transactional services using a Cash In Advance constraint that stipulates that individuals with wealth $w_{t}$ and money holdings $m_{t}$ can only consume $\min \left(w_{t}, \frac{m_{t}}{\varepsilon}\right)$. When $i^{K}>0$, money is held only for transaction services. When $i^{K}=0$ money is also held as a safe store of value, which competes with its transaction services. This model has no equilibrium with $i^{K}<0$, because then money dominates other safe assets. Hence there is a zero lower bound $i^{K} \geq 0$. The model becomes isomorphic to our basic model in the cashless limit as $\varepsilon \rightarrow 0$. We develop this setup next.

The demand for real money balances for transactional services is $\varepsilon W_{t}^{K}$ and $\varepsilon W_{t}^{N}$ for Knightians and Neutrals respectively. We assume that the money supply is $\varepsilon M^{\varepsilon}$ with $M^{\varepsilon}=$ $\frac{X}{\theta}$. When the Poisson shock hits, the government buys back part of the money stock so that the money supply is $\varepsilon M^{\varepsilon, \mu}$ with $M^{\varepsilon, \mu}=\mu \frac{X}{\theta}$. This ensures that money is adequate and output is at potential after the Poisson shock. In order to finance this purchase, we let the government issue short term debt, the principal of which is rolled over and the interest of which is paid using a tax on the dividends of risky assets. Importantly, the ability to retire the extra money after the Poisson shock requires the government to have the fiscal capacity to raise these taxes, a key concept that we analyze at length in Section 3.

After the Poisson shock, the value $V^{\mu}$ of the safe tranches of trees is a fraction $\rho$ of the total value of assets excluding money (trees and government debt). And we therefore have

$$
\theta\left(\frac{1}{\rho} V^{\mu}+\varepsilon M^{\varepsilon, \mu}\right)=\mu X
$$

i.e.

$$
V^{\mu}=\rho \mu(1-\varepsilon) \frac{X}{\theta}
$$

The equilibrium equations are now, denoting the real money supply as $M=\varepsilon M^{\varepsilon}$,

$$
\begin{gathered}
r^{K} V^{\mu}=\delta^{\mu} \xi X, \\
r V^{r}=\left(\delta-\delta^{\mu}\right) \xi X, \\
\dot{W}_{t}^{K}=-\theta W_{t}^{K}+\alpha(1-\delta) \xi X+r^{K}(1-\varepsilon) W_{t}^{K}, \\
\dot{W}_{t}^{N}=-\theta W_{t}^{N}+(1-\alpha)(1-\delta) \xi X+r(1-\varepsilon) W_{t}^{N}, \\
\varepsilon\left(W_{t}^{K}+W_{t}^{N}\right) \leq \varepsilon M^{\varepsilon} \quad \text { with equality if } r^{K}>0
\end{gathered}
$$




$$
\begin{gathered}
W_{t}^{K}+\varepsilon W_{t}^{N} \leq V^{\mu}+\varepsilon M^{\varepsilon}, \\
W_{t}^{K}+W_{t}^{N}=V^{\mu}+V^{r}+\varepsilon M^{\varepsilon},
\end{gathered}
$$

and the requirement that

$$
r^{K} \geq 0
$$

When $r^{K}>0$, we always have $\xi=1$ as long as money is adequate $M^{\varepsilon}=\frac{X}{\theta}$, which we assume throughout. ${ }^{10}$ The interesting case for us is when $r^{K}=0$, for then $\xi$ is determined from equilibrium in the safe asset market, in which part of money is used for store of value.

At $r^{K}=0$ the supply for safe assets (safe tranches and money) is

$$
\rho \mu(1-\varepsilon) \frac{X}{\theta}+\varepsilon M^{\varepsilon}
$$

The demand for safe assets (safe tranches and money) is

$$
\varepsilon\left(W^{K}+W^{N}\right)+(1-\varepsilon) W^{K}
$$

which can be written as:

$$
\varepsilon \frac{\xi X}{\theta}+(1-\varepsilon) W^{K}
$$

Replacing Knightian wealth $W^{K}=\alpha(1-\delta) \frac{\xi X}{\theta}$ into this expression yields equilibrium output:

$$
\xi=\frac{\rho \mu+\frac{\varepsilon}{1-\varepsilon} M^{\varepsilon} \frac{\theta}{X}}{\frac{\varepsilon}{1-\varepsilon}+\alpha(1-\delta)},
$$

which converges to the expression in the basic model in the cashless limit as $\varepsilon \rightarrow 0 .{ }^{11,12}$

\footnotetext{
${ }^{10}$ We can have $\xi<1$ even when $r^{K}>0$ if money is scarce $M^{\varepsilon}<\frac{X}{\theta}$. These effects are standard in Keynesian models and are not our focus here.

${ }^{11}$ One interesting feature of this model is that there is an additional mechanism by which the recession helps eliminate the excess demand for safe assets, by reducing the money balances held by Neutrals and hence expanding the safe stores of value available to Knightians. In other words, as rates fall to zero, money itself becomes indistinguishable from other safe assets; to the extent that money provides other important services to the economy (e.g. transactional), its use for store of value can be contractionary (it is akin to an upward shift in money demand)

${ }^{12}$ If $\varepsilon$ is small, money does not relax much the fiscal capacity of the government and hence its ability to create safe assets: Issuing money while at the zero bound is equivalent to issuing short-term bonds, and both are constrained by the long-term fiscal capacity of the government. Indeed, after the Poisson shock, then the government must raise taxes to retire the additional money that it has issued before the Poisson shock. Failing to do so requires accepting a reduction in safe interest rates after the Poissson shock and results in an overstimulation of output - a form of forward guidance policy discussed in Section 4.
} 


\section{Balance Sheet and Fiscal Policies in SAM}

Could government policy and instruments reduce the severity of the safety trap? In particular, could the government affect the supply and demand for safe assets in productive ways?

In this section we focus on the role of public debt and (central bank) balance sheet policies as well as fiscal policies (redistribution, government spending), and postpone a discussion of monetary policy to the next section. We argue that the government does have a role to play but that its margin of action is constrained by its fiscal capacity.

\subsection{Public Debt and Balance Sheet Policies}

We start by introducing public debt and discussing the role of public purchases and sales of such debt. To isolate the insights of this section we assume for now that private trees cannot be tranched at all $(\rho=0)$, and hence cannot produce safe assets by themselves.

We first introduce short-term public debt. We show that the if the government has spare fiscal capacity, then it can increase the supply of public debt, and rebating the proceeds of the issuance to private agents. This increases the supply of safe assets and stimulates the economy.

We then study the impact of Quantitative Easing (QE) policies that swap trees for shortterm public debt. We should be clear that we are using the term QE with some liberality to describe policies that swap risky assets for safe assets such as the recent QE1 in the U.S., LTRO in Europe, and many other lender of last resort central bank interventions. These policies act to increase the supply of safe assets and therefore help reduce the safety premium. If the economy is in a safety trap and output is below potential, they have a stimulating effect on output.

Next, we introduce long-term public debt and study Operation Twist (OT) policies that swap long-term debt for short-term debt. These policies encompass the QE2 and QE3 policies undertaken in the U.S. In contrast to QE policies, we show that such policies can

backfire. Basically, replacing long term debt by short term debt reduces the supply of safe assets. This happens despite the fact that short term debt is safe. The reason is that long term debt has a multiplier effect on safe asset creation which short term debt does not have: Long term debt is a "bearish" asset that can be combined with risky private assets to create 
safe assets. If the economy is in a safety trap so that output is below potential, OT policies have a depressing effect on output.

All these policies act on the supply of safe assets. If the government is not against its future fiscal capacity constraint, issuing more public debt is effective because it increases the supply of safe assets. The same goes for QE. OT is detrimental because it reduces the supply of safe assets.

\subsubsection{Short-Term Public Debt and Fiscal Capacity}

Introducing short-term public debt. The government taxes dividends, $\delta X$. The tax rate is $\tau^{\mu}$ after the Poisson shock occurs, while the tax rate before the Poisson shock is set to a value $\tau$ that satisfies the government flow budget constraint. The government issues a fixed amount of risk-free bonds that capitalize future tax revenues and pays a variable rate $r_{t}^{K}$. It is the latter feature that makes this debt "short-term," since its value remains constant over time as its coupons vary with the riskless rate. The proceeds of the sales of these bonds are rebated lump-sum to agents at date 0 . Hence in this model government debt acts exactly like tranching, with $\tau^{\mu}$ playing the role of $\rho$.

Let the value of public debt be given by $D$, then we have

$$
D=\tau^{\mu} \mu \frac{X}{\theta}
$$

The equilibrium is described by the following equations:

$$
\begin{gathered}
r^{K} D=\tau \delta X, \\
r V=\delta(1-\tau) X, \\
\dot{W}_{t}^{K}=-\theta W_{t}^{K}+\alpha(1-\delta) X+r^{K} W_{t}^{K}, \\
\dot{W}_{t}^{N}=-\theta W_{t}^{N}+(1-\alpha)(1-\delta) X+r W^{N} . \\
W_{t}^{K}+W_{t}^{N}=D+V, \\
W_{t}^{K} \leq D \text { and } r^{K} \leq r .
\end{gathered}
$$


At a steady state of the constrained regime we have

$$
W^{K}=D=\tau^{\mu} \mu \frac{X}{\theta}, \quad W^{N}=V=\left(1-\tau^{\mu} \mu\right) \frac{X}{\theta}
$$

and

$$
\begin{gathered}
\delta \tau=\tau^{\mu} \mu-\alpha(1-\delta), \\
r^{K}=\delta \theta-(1-\delta) \theta \frac{\alpha-\tau^{\mu} \mu}{\tau^{\mu} \mu}, \\
r=\delta \theta+(1-\delta) \theta \frac{\alpha-\tau^{\mu} \mu}{1-\tau^{\mu} \mu} .
\end{gathered}
$$

The economy is in the constrained regime if and only if $\alpha>\tau^{\mu} \mu$, which we assume. The safety premium is then given by

$$
r-r^{K}=\theta(1-\delta) \frac{\alpha-\tau^{\mu} \mu}{\tau^{\mu} \mu\left(1-\tau^{\mu} \mu\right)} \geq 0 .
$$

In this model, the supply of safe assets comes entirely in the form of short-term public debt. The supply of the latter is determined by a notion of fiscal capacity, as measured by $\tau^{\mu} \mu$. The larger fiscal capacity, the more short-term debt the government can issue, the larger the supply of safe assets and the lower the safety premium.

If the economy is in a safety trap where the safe interest rate is fixed at $\underline{r}^{K}$ and output is below potential with $\xi<1$, then in increasing public debt from $D$ to $\hat{D}>D$ stimulates output, increasing $\xi$ to $\hat{\xi}$ where

$$
\hat{\xi}=\frac{\hat{D}}{D} \xi>\xi
$$

Increasing the supply of public debt to $\hat{D}$ requires the government to have spare fiscal capacity, that is to have the ability to raise more taxes after the Poisson shock

$$
\hat{\tau}^{\mu}=\frac{\hat{D}}{D} \tau^{\mu}>\tau^{\mu}
$$

The government's ability to expand this supply either because it has excess fiscal capacity or because it can implicitly tranch assets in a way the private sector cannot, which gives it a comparative advantage in the production of safe assets. This result does not require the extreme assumption $\rho=0$ that we have made solely to simplify the exposition. Indeed, the comparative advantage of the government in the production of safe assets is present as long 
as there are some limits to the tranching of private assets $(\rho<1)$. It is only when there are no limits to the tranching of private assets $(\rho=1)$ that this comparative advantage disappears and that the supply of public debt becomes irrelevant - a form of Ricardian equivalence. ${ }^{13}$

Fiscal capacity limits. In the rest of the paper, we investigate policy options for the government when it is against its long-run fiscal capacity, with limited ability to increase future taxes. For this reason, we fix $\tau^{\mu}$ and treat it as a hard fiscal capacity constraint.

\subsubsection{Quantitative Easing}

We remind the reader that we are using the term QE with some abuse to encompass policies that swap risky assets for safe assets such as QE1, LTRO, and many other lender of last resort central bank interventions. We model QE as follows. The government purchases trees and issues additional short-term debt. Let $\hat{\beta}^{g}$ be the fraction of the trees purchased by the government. Let $\hat{D}$ be the value of government debt and let $\hat{\tau}^{\mu}$ be the new value of taxes after the Poisson shock (which must satisfy $\hat{\tau}^{\mu} \leq \tau^{\mu}$ ). We continue to assume that the stock of short-term debt is unchanged before and after the Poisson shock. We have

$$
\hat{D}=\hat{\tau}^{\mu}\left(1-\hat{\beta}^{g}\right) \mu \frac{X}{\theta}+\hat{\beta}^{g} \mu \frac{X}{\theta} .
$$

As long as

$$
\hat{\tau}^{\mu}\left(1-\hat{\beta}^{g}\right)+\hat{\beta}^{g}>\tau^{\mu},
$$

the safe asset shortage is alleviated by this policy: $r^{K}$ increases, $r$ decreases, and the safety premium shrinks.

QE here works not so much by removing private assets from private balance sheets, but

\footnotetext{
${ }^{13}$ This mechanism has some commonality with the idea in Holmström and Tirole (1998) that the government has a comparative advantage in providing liquidity. In their model this result arises from the assumption that some agents (consumers in their model) lack commitment and hence cannot borrow because they cannot issue securities that pledge their future endowments. This can result in a scarcity of stores of value. The government can alleviate this scarcity by issuing public debt and repaying this debt by taxing consumers. The proceeds of the debt issuance can actually be rebated to consumers. At the aggregate level, this essentially relaxes the borrowing constraint of consumers: They borrow indirectly through the government. The comparative advantage of the government in providing liquidity arises from its unique regalian taxation power: It is essentially better than private lenders at collecting revenues from consumers. In the case where consumers face no commitment problems in the securitization of their future income, there are no borrowing constraints, public debt is irrelevant, Ricardian equivalence is recovered and the comparative advantage of the government disappears. Hence the imperfect ability of consumers to securitize their future income plays a similar role in the theory of Holmstrom and Tirole (1998) as the assumption of imperfect tranchability in ours.
} 
rather by injecting public assets into private balance sheets. In other words, QE works by increasing the supply of safe assets. The government can expand this supply even when it doesn't have excess fiscal capacity because it can implicitly tranch assets in a way the private sector cannot, which gives it a comparative advantage in safety transformation. The key difference between QE and simply issuing more public debt is what the government does with the proceeds from the debt issuance. In QE, the government uses the proceeds to purchase private risky assets instead of simply rebating them to private agents. By doing so, it is able to run up its debt without stretching its future fiscal capacity.

If the economy is in a safety trap where the safe interest rate is fixed at $\underline{r}^{K}$ and output is below potential with $\xi<1$, then QE acts by stimulating output, increasing it from $\xi$ to $\hat{\xi}$ where ${ }^{14,15}$

$$
\hat{\xi}=\frac{\hat{D}}{D} \xi>\xi
$$

\subsubsection{Long-Term Public Debt and Operation Twist}

We now analyze Operation Twist (OT) policies that swap long-term debt for short-term debt. These policies encompass QE2 and QE3. To do so, we first need to introduce longterm public debt into the model.

Introducing long-term public debt. The key aspect of long-term debt that we wish to capture here is its bearish nature (i.e., its ability to generate capital gains during periods of distress). In reality this feature stems from its fixed coupons and the drop in safe rates during contractions. While this drop holds in our model in the pre-Poisson phase when

\footnotetext{
${ }^{14}$ In general, QE might require a transition phase where the government raises taxes before the Poisson shock in order to gradually acquire those assets. The analysis in the main text assumes that this adjustment has taken place and examines the consequences of the eventual buildup of such a portfolio. After this portfolio buildup phase, taxes are actually lower at $\hat{\tau}$ determined by:

$$
\hat{\tau}=\underline{r}^{K} \frac{1}{\delta \theta} \frac{\tau^{\mu} \mu}{\xi}-\frac{1}{\theta} \hat{\beta}^{g}<\tau=\underline{r}^{K} \frac{1}{\delta \theta} \frac{\tau^{\mu} \mu}{\xi} .
$$

${ }^{15}$ In certain circumstances, it is possible to design QE policies that do not require a buildup phase with increased taxes before the Poisson shock, i.e. such that the debt issuance more than covers the asset purchases. The condition is $\hat{\beta}^{g} \frac{\hat{\xi} X}{\theta} \leq \hat{D}-D$, where $\hat{\xi}=\frac{\hat{D}}{D} \xi$, which can be shown after some manipulation to boil down to

$$
\xi \leq \frac{\tau^{\mu}}{\hat{\tau}^{\mu}\left(1-\hat{\beta}^{g}\right)+\hat{\beta}^{g}} \frac{\hat{\tau}^{\mu}\left(1-\hat{\beta}^{g}\right)+\hat{\beta}^{g}-\tau^{\mu}}{\hat{\beta}^{g}} \mu .
$$

Hence if the economy is depressed enough, then it is possible to build up a QE portfolio without immediately raising taxes, that stimulates output.
} 
safety demand rises, it does not at the Poisson event since uncertainty is resolved once this shock takes place. Rather than adding shocks within the post-Poisson phase-for example a fall in interest rates induced by a deleveraging/increase in desired savings shock could be roughly captured by a decrease in $\theta$ after the Poisson shock - we introduce the bearishness of long term debt through a simple transfer mechanism.

Let us assume that after the Poisson shock, a fraction $\phi$ of tax revenues $\tau^{\mu} \mu \delta$ is committed to servicing long term debt $D^{\text {long }}$, and the remaining fraction $(1-\phi)$ is committed to servicing short term debt $D^{\text {short }}$. Before the Poisson shock, we assume that tax revenues and debt policy are adjusted as follows: First, the value of outstanding short term debt is the same as after the Poisson shock (this is what makes it short term debt)

$$
D^{\text {short }}=(1-\phi) \tau^{\mu} \mu \frac{X}{\theta}
$$

Second, the value of long term debt is kept at a level

$$
D^{l o n g}=\psi \tau^{\mu} \phi \mu \frac{X}{\theta}
$$

below its value $\phi \mu \frac{X}{\theta}$ after the Poisson shock, where $\psi \in(0,1)$. This is our simple mechanism to introduce the macro insurance aspect of long term debt; the lower is $\psi$, the larger is the macro insurance aspect of long term debt. The required tax rate $\tau$ before the Poisson shock so that such a policy is feasible is defined implicitly by

$$
r^{K} D^{\text {short }}+r D^{\text {long }}=\tau \delta X
$$

In this context the value of trees is

$$
V=\left[1-\tau^{\mu} \mu(1-(1-\psi) \phi)\right] \frac{X}{\theta}
$$

which is increasing in $\phi$, the share of long term debt in public debt. This effect is stronger, the larger is the insurance aspect of long term debt (the lower is $\psi$ ). The reason is that the presence of long term debt acts as a hedge for risky trees, and therefore allows the transformation of risky assets into safe assets through portfolio construction.

Let $x$ be the fraction of the trees that uses all the stock of long term debt to generate safe assets. This fraction $x$ is determined from the condition that the value of a safe asset 
can not jump at the Poisson event:

$$
x\left[1-\tau^{\mu} \mu(1-(1-\psi) \phi)\right] \frac{X}{\theta}+\psi \phi \tau^{\mu} \mu \frac{X}{\theta}=x\left(1-\tau^{\mu}\right) \mu \frac{X}{\theta}+\phi \tau^{\mu} \mu \frac{X}{\theta},
$$

i.e.

$$
x=\frac{\phi(1-\psi) \tau^{\mu} \mu}{1-\mu+\phi(1-\psi) \tau^{\mu} \mu} .
$$

The total supply of safe assets is then given by

$$
\begin{aligned}
V^{\mu} & =D^{\text {short }}+\frac{1}{\psi} D^{\text {long }}+x\left(1-\tau^{\mu}\right) \mu \frac{X}{\theta} \\
& =\tau^{\mu} \mu \frac{X}{\theta}+x\left(1-\tau^{\mu}\right) \mu \frac{X}{\theta},
\end{aligned}
$$

which can be rewritten as

$$
V^{\mu}=\Gamma\left(\phi, \psi, \mu, \tau^{\mu}\right) \tau^{\mu} \mu \frac{X}{\theta}
$$

where

$$
\Gamma\left(\phi, \psi, \mu, \tau^{\mu}\right)=1+\frac{\phi(1-\psi)\left(1-\tau^{\mu}\right) \mu}{1-\mu+\phi(1-\psi) \tau^{\mu} \mu} \geq 1 .
$$

The supply of risky assets is simply given by the residual

$$
V^{r}=\frac{X}{\theta}-V^{\mu}
$$

The safe and risky interest rates can be computed to be

$$
\begin{gathered}
r^{K}=\delta \theta-(1-\delta) \theta \frac{\alpha-\Gamma\left(\phi, \psi, \mu, \tau^{\mu}\right) \tau^{\mu} \mu}{\Gamma\left(\phi, \psi, \mu, \tau^{\mu}\right) \tau^{\mu} \mu}, \\
r=\delta \theta+(1-\delta) \theta \frac{\alpha-\Gamma\left(\phi, \psi, \mu, \tau^{\mu}\right) \tau^{\mu} \mu}{1-\Gamma\left(\phi, \psi, \mu, \tau^{\mu}\right) \tau^{\mu} \mu} .
\end{gathered}
$$

Operation twist. Clearly $r$ and $r^{K}$ are respectively decreasing and increasing in $\Gamma$, and $\Gamma$ is increasing in $\phi$. Therefore $r$ is decreasing in $\phi$ and $r^{K}$ is increasing in $\phi$. If we interpret OT as a shortening of public debt maturity held by the private sector, i.e. a lowering of $\phi$, we have that OT decreases $r^{K}$ and increases $r$. That is, replacing long term debt by short term debt reduces the supply of safe assets. This happens despite the fact that short term debt is safe. Long term debt is a bearish asset that can be combined with risky assets to create safe assets, thus an expansion in long term debt not only creates the safe debt that is intrinsic to backed public debt, but also creates a hedge that transforms some risky private 
assets into safe assets. In contrast, short term debt does not have this additional hedging effect and only expands the supply of safe assets one for one.

If the economy is in a safety trap where the safe interest rate is fixed at $\underline{r}^{K}$ and output is below potential with $\xi<1$, then an OT policy that lowers $\phi$ to $\hat{\phi}<\phi$, further reduces $\xi$ to $\hat{\xi}$ where ${ }^{16}$

$$
\hat{\xi}=\frac{\Gamma\left(\hat{\phi}, \psi, \frac{\mu}{\hat{\xi}}, \tau^{\mu}\right)}{\Gamma\left(\phi, \psi, \frac{\mu}{\xi}, \tau^{\mu}\right)} \xi<\xi .
$$

A narrative often put forth by central bank officials to justify OT policies is the following: Because asset markets are segmented, the central bank can increase the price of long-term government bonds by purchasing such bonds; this also increases the incentives of firms to invest because investment can be financed with long-term private debt, which is a substitute to long-term public debt and hence stimulates the economy. Our model challenges this narrative: In a safety trap, OT is detrimental to output, and the mechanism trough which OT operates is very different. Of course in practice, both mechanisms might be operative, and we think that it would be interesting to build models that features them both. At this stage, our results should be interpreted as suggesting that there may be forces limiting the effectiveness of these policies.

\subsection{Fiscal Policy in SAM}

We identify two levers for fiscal policy in a SAM environment. The first lever acts on the demand for safe assets by taxing away the wealth of Knightians. The corresponding revenues can either be redistributed to Neutrals (as explained in Section 3.2.1), or used to increase government spending (as explained in Section 3.2.2). In both cases, such policies stimulate the economy. The second lever acts on the supply of safe assets. The government's ability to supply safe assets is determined by its fiscal capacity. Once a country's fiscal capacity is used up, the only way for the government to increase its supply of safe assets is to engage in credible future fiscal consolidation. This allows the government to sustain higher debt, enhances the government's ability to create safe assets, and therefore boosts the economy.

\footnotetext{
${ }^{16} \mathrm{~A}$ similar result can be obtained in the endogenous tranching model, since output is an increasing function of $r^{K}$.
} 


\subsubsection{Redistributive Policies}

Recall that the market equilibrium is restored by reducing the wealth of Knightians, either by a drop in the return of the assets they hold, or through a recession. Policy can also play that role. In this section, we consider the effects of policies that redistribute income and wealth away from Knightians and toward Neutrals. We show that in a safety trap, such redistribution stimulates the economy. Importantly, that redistribution can be welfareneutral for Knightians once the expansionary effect of the policy is taken into account.

We find it most natural to consider a setup where labor income rather than capital income is taxed, and we allow for differentiated labor income taxes between Knightians $\tau^{K}$ and Neutrals $\tau^{N}$. The average tax rate in the economy is

$$
\tau=\tau^{K} \alpha+\tau^{N}(1-\alpha)
$$

We have

$$
\begin{gathered}
r^{K} D=\tau(1-\delta) X, \\
r V=\delta X, \\
D=\frac{(1-\delta) \tau^{\mu}}{\delta+(1-\delta) \tau^{\mu}} \mu \frac{X}{\theta} .
\end{gathered}
$$

And we have:

$$
\begin{gathered}
\dot{W}_{t}^{K}=-\theta W_{t}^{K}+\alpha(1-\delta)\left(1-\tau^{K}\right) X+r^{K} W_{t}^{K} \\
\dot{W}_{t}^{N}=-\theta W_{t}^{N}+(1-\alpha)(1-\delta)\left(1-\tau^{N}\right) X+r W_{t}^{N} \\
W_{t}^{K}=D, \\
W_{t}^{N}=V .
\end{gathered}
$$

The equilibrium rates are:

$$
\begin{gathered}
r^{K}=\theta-\alpha(1-\delta)\left(1-\tau^{K}\right) \frac{\theta}{\frac{(1-\delta) \tau^{\mu}}{\delta+(1-\delta) \tau^{\mu}} \mu}, \\
r=\frac{\theta}{1+\frac{(1-\alpha)(1-\delta)\left(1-\tau^{N}\right)}{\delta}} .
\end{gathered}
$$

Now suppose that the economy is in the constrained regime and in a safety trap where the safe interest rate is at $\underline{r}^{K}$ and the government is using all its debt capacity. In this scenario an 
increase in taxes on Knightians $\tau^{K}$ which is used to reduce taxes on Neutrals $\tau^{N}$ stimulates the economy pushing $\xi$ to $\hat{\xi}$ where

$$
\hat{\xi}=\xi \frac{1-\tau^{K}}{1-\hat{\tau}^{K}}>\xi
$$

This is because such redistributive policy reduces the demand for safe assets (without affecting the supply for safe assets).

One remarkable property of this policy is that even though the tax rate on Knightians is increased, Knightians are not worse off. In fact, Knightians are exactly as well off. Indeed, the safe interest rate is unchanged at $\underline{r}^{K}$ and the income of Knightian newborns is also unchanged at $\alpha(1-\delta)\left(1-\hat{\tau}^{K}\right) \hat{\xi} X=\alpha(1-\delta)\left(1-\tau^{K}\right) \xi X$. For Neutrals, the effects are more complex. Overall, the consumption of Neutrals increases from $\xi X-\theta D$ to $\hat{\xi} X-$ $\theta D$ in every period, but this effect is unequally distributed among agents. The income of Neutral newborns increases in every period, and so does the initial value of the assets held by Newborns at the moment when the policy change is implemented. However, the interest rate $r$ decreases. As a result, Newborns who live for a long time before consuming end up consuming less, while Newborns who live for a short time before consuming end up consuming more. Without putting more structure on preferences, the effects of the welfare of Neutrals are ambiguous. One possibility is to assess the welfare of Neutrals using a discounted expected consumption metric with discount factor $\beta \in(0,1)$. Then Neutrals are better off as long as $\beta$ is low enough. ${ }^{17}$

\subsubsection{Short-Term Fiscal Stimulus and Long-Term Fiscal Consolidation}

We now introduce government spending into the model. We assume that the government spends a fraction $G$ of output $X$ in every period until the Poisson shock hits, and a fraction

\footnotetext{
${ }^{17}$ Interestingly, because the tax change stimulates the economy, the reduction in tax rate on Neutrals is larger (the tax increase on Knigthian increases the tax base). Indeed using

$$
\hat{\tau} \hat{\xi}=\tau \xi
$$

we find

$$
\left(\tau^{N}-\hat{\tau}^{N}\right)(1-\alpha)(1-\delta)=\left(1-\frac{\xi}{\hat{\xi}}\right)\left[\tau^{K} \alpha(1-\delta)+\tau^{N}(1-\alpha)(1-\delta)\right]+\left(\hat{\tau}^{K}-\tau^{K}\right) \alpha(1-\delta) .
$$

The second term on the right-hand side represents the reduction in the tax on Knightians at constant output. The first term on the right-hand-side represents the extra reduction in the tax on Knightians made possible by the associated increase in output.
} 
$G^{\mu}$ of output $\mu X$ after it. We index by $\tau^{d}$ the tax revenues allocated to paying the interest on debt and by $\hat{\tau}$ the total tax revenues, so that $\hat{\tau}-\tau^{d}$ is devoted to financing the flow of government expenditures. Finally, and for expository simplicity, we assume in the first part of this section that only dividends are taxed. We consider the case where labor income is taxed in the second part of the section. With these changes, the new equations in the system are:

$$
\begin{gathered}
r^{K} D=\tau^{d} \delta X \\
r V=\delta(1-\hat{\tau}) X \\
G X=\left(\hat{\tau}-\tau^{d}\right) \delta X \\
D=\frac{\tau^{\mu} \delta-G^{\mu}}{\delta-G^{\mu}} \mu \frac{X\left(1-G^{\mu}\right)}{\theta} .
\end{gathered}
$$

And we still have:

$$
\begin{gathered}
\dot{W}_{t}^{K}=-\theta W_{t}^{K}+\alpha(1-\delta) X+r^{K} W_{t}^{K}, \\
\dot{W}_{t}^{N}=-\theta W_{t}^{N}+(1-\alpha)(1-\delta) X+r W_{t}^{N}, \\
W_{t}^{K}=D, \\
W_{t}^{N}=V .
\end{gathered}
$$

The new equilibrium rates are:

$$
\begin{gathered}
r^{K}=\delta \theta-\theta(1-\delta)\left(\frac{\alpha}{\frac{\tau^{\mu} \delta-G^{\mu}}{\delta-G^{\mu}} \mu} \frac{1}{1-G^{\mu}}-1\right), \\
r=\delta \theta+\theta(1-\delta)\left(1-\frac{1-\alpha}{1-\frac{\tau^{\mu} \delta-G^{\mu}}{\delta-G^{\mu}} \mu} \frac{1}{(1-G)+\frac{\frac{\tau^{\mu} \delta-G^{\mu}}{\delta-G^{\mu}} \mu}{1-\frac{\tau^{\mu} \delta-G^{\mu}}{\delta-G^{\mu}} \mu}\left(G^{\mu}-G\right)}\right) .
\end{gathered}
$$

and the system is in the constrained regime (which we assume) if and only if

$$
\frac{\alpha}{1-\alpha} \frac{1-\frac{\tau^{\mu} \delta-G^{\mu}}{\delta-G^{\mu}} \mu}{\frac{\tau^{\mu} \delta-G^{\mu}}{\delta-G^{\mu}} \mu}>\frac{1}{1+\frac{1}{1-\frac{\tau^{\mu} \delta-G \mu}{\delta-G \mu} \mu} \frac{G^{\mu}-G}{1-G^{\mu}}} .
$$

Now suppose the economy is in a safety trap where the safe interest rate is at $\underline{r}^{K}$ and the government is using all its debt capacity. In this scenario, a fiscal expansion in $G$ is powerless 
in stimulating output because it affects neither the demand nor the supply of safe assets, and hence leaves the safe interest rate $r^{K}$ unaffected. Instead, this form of government policy only affects the safety spread and interest rate $r$.

By contrast, a credible decrease of $G^{\mu}$ to $\hat{G}^{\mu}<G^{\mu}$ stimulates output pushing $\xi$ to $\hat{\xi}$ where

$$
\hat{\xi}=\xi \frac{\left(1-\hat{G}^{\mu}\right) \frac{\tau^{\mu} \delta-\hat{G}^{\mu}}{\delta-\hat{G}^{\mu}}}{\left(1-G^{\mu}\right) \frac{\tau^{\mu} \delta-G^{\mu}}{\delta-G^{\mu}}}>\xi
$$

The reason is that for a given fiscal capacity, lower future government spending frees up fiscal resources and allows the government to sustain higher (safe) public debt. If the government utilizes this increased capacity in the short run, it increases the supply of safe assets, thereby alleviating their shortage. As far as government spending is concerned, our model prescribes delayed fiscal consolidations as a remedy to safety traps.

This conclusion has both similarities and differences with the conventional policy recommendation. Indeed, proponents of fiscal stimulus in recessions typically favor a two-pronged approach combining short term fiscal stimulus for Keynesian reasons with long-term fiscal restraint to avoid generating doubts about fiscal sustainability. The short-term stimulus is the central piece of the argument, and long-run fiscal responsibility is added for robustness, almost as an afterthought. Our model identifies the same levers but reverses the pecking order by making long-run fiscal consolidation the key policy instrument since in its absence the government may not be able to create the safe debt that is in short supply. ${ }^{18}$

These stark conclusions depend partly on the maintained assumption that government spending is financed by taxes rather than by issuing debt (because the government is against its future fiscal capacity to that $\tau^{\mu}$ cannot be increased), and that the taxes are levied on capital income (dividends). To illustrate this point, we consider two alternative scenario: one in which the increase in government spending is accompanied by a buildup in public debt (which requires an increase in $\tau^{\mu}$ ), and one in which taxes are levied on labor income.

\footnotetext{
${ }^{18}$ This analysis also separates SAM, which emphasizes the effect of safe asset supply, from Keynesian or New Keynesian liquidity trap economics which emphasizes the role of aggregate demand. The Keynesian view of liquidity trap argues in favor of short term fiscal stimulus, which is presumed to be especially effective at the zero lower bound because of the absence of crowding out effects through higher interest rates. The New Keynesian view emphasizes the role of inflation: Fiscal multipliers are large at the zero lower bound because government spending creates inflation and hence lowers real interest rates. (Christiano, Eichnbaum and Rebelo 2011); backloaded fiscal stimulus leads to more bang for the buck because it leads to more cumulated inflation (Farhi and Werning 2012). In contrast to the Keynesian view, and somewhat in line with the New Keynesian view, our mechanism works through long run fiscal adjustments. Although in contrast to both the Keynesian and New Keynesian views, it works through reductions in future government spending.
} 
Short-term stimulus accompanied by a public debt buildup. Here we depart momentarily from our maintained assumption that $\tau^{\mu}$ is fixed because the government is against its future fiscal capacity constraint. We consider what happens when the government has enough spare future fiscal capacity to finance part of the increase in government spending from $G$ to $\hat{G}$ by a buildup in debt, which in turn requires an increase in $\tau^{\mu}$ to $\hat{\tau}^{\mu}>\tau^{\mu}$. In a safety trap when the interest rate is at $\underline{r}^{K}$, this stimulates output, increasing $\xi$ to $\hat{\xi}$ where

$$
\hat{\xi}=\xi \frac{\hat{\tau}^{\mu} \delta-G^{\mu}}{\tau^{\mu} \delta-G^{\mu}}>\xi
$$

It is important to note that the government could have increased its public debt without increasing government spending, rebating the entire proceeds of the debt issuance to private agents instead, with the same stimulative benefits for the economy. In other words, what really matters is that there be an increase in public debt, which boosts the supply of safe assets, not the increase in government spending per se.

Short-term stimulus and long-term fiscal consolidation with taxes on labor income. Here we assume that government spending is financed by taxes on labor income as in Section 3.2.1. This matters because our environment is non-Ricardian, and so the distribution of taxes is important. The system is now:

$$
\begin{gathered}
r^{K} D=\tau^{d}(1-\delta) X \\
r V=\delta X \\
G X=\left(\hat{\tau}-\tau^{d}\right)(1-\delta) X \\
D=\frac{(1-\delta) \tau^{\mu}-G^{\mu}}{\delta+(1-\delta) \tau^{\mu}-G^{\mu}} \mu \frac{X\left(1-G^{\mu}\right)}{\theta} .
\end{gathered}
$$

And we have:

$$
\begin{gathered}
\dot{W}_{t}^{K}=-\theta W_{t}^{K}+\alpha(1-\delta)(1-\hat{\tau}) X+r^{K} W_{t}^{K} \\
\dot{W}_{t}^{N}=-\theta W_{t}^{N}+(1-\alpha)(1-\delta)(1-\hat{\tau}) X+r W_{t}^{N} \\
W_{t}^{K}=D \\
W_{t}^{N}=V .
\end{gathered}
$$


The equilibrium rates are:

$$
\begin{gathered}
r^{K}=\theta-\alpha(1-\delta)(1-\hat{\tau}) \frac{\theta}{\frac{(1-\delta) \tau^{\mu}-G^{\mu}}{\delta+(1-\delta) \tau^{\mu}-G^{\mu}} \mu\left(1-G^{\mu}\right)}, \\
r=\frac{\theta}{1+\frac{(1-\alpha)(1-\delta)(1-\hat{\tau})}{\delta}}
\end{gathered}
$$

Now assume that the economy is in the constrained regime and in a safety trap where the safe interest rate is at $\underline{r}^{K}$ and the government is using all its debt capacity. In this scenario a fiscal expansion in $G$ financed by an increase in labor taxes stimulates output pushing $\xi$ to $\hat{\xi}$ where

$$
\hat{\xi}=\xi \frac{1-\frac{G}{1-\delta}}{1-\frac{\hat{G}}{1-\delta}}>\xi .
$$

A fiscal stimulus financed by a tax on labor income is successful at stimulating output. This is a contrast with the case where the increase in government spending is financed by a tax on capital income (dividends). This is because contrary to taxes on capital income, taxes on labor income reduce the demand for safe assets by reducing the income of Knightian newborns.

The conclusion that a credible decrease of $G^{\mu}$ to $\hat{G}^{\mu}<G^{\mu}$ stimulates output remains valid when labor income rather than capital income is taxed. Indeed, such a fiscal consolidation pushes $\xi$ to $\hat{\xi}$ where $\hat{\xi}$ is given by exactly the same formula as when capital income is taxed:

$$
\hat{\xi}=\xi \frac{\left(1-\hat{G}^{\mu}\right) \frac{\tau^{\mu} \delta-\hat{G}^{\mu}}{\delta-\hat{G}^{\mu}}}{\left(1-G^{\mu}\right) \frac{\tau^{\mu} \delta-G^{\mu}}{\delta-G^{\mu}}}>\xi
$$

Self-fulfilling debt crises. In the appendix (Section 7.1.3), we discuss the potential for self-fulfilling safe debt crises, in which case the value of fiscal consolidation is exacerbated. This captures the instabilities that have characterized the so called periphery economies of the Eurozone: Given the importance of fiscal capacity in the production of safe assets, and the centrality of the latter in determining equilibrium output in a SAM environment, an economy that is near its fiscal limits is susceptible to runs on its public debt and to destabilizing feedback loops. 


\section{Forward Guidance}

In the next section we will contrast safety and liquidity traps. But before doing so we discuss the effectiveness of forward guidance type policies (commitments to low future interest rates) within the context of SAM. These policies are usually advocated in the context of standard New-Keynesian liquidity trap models. They involve committing to keeping interest rates low once the economy recovers. Indeed in Section 5, we modify our model to capture a liquidity trap and show that such policies increase asset values, boost demand through a wealth effect, and hence stimulate the economy.

By contrast, we show that such commitments are ineffective at stimulating output in a safety trap since they are powerless at increasing the value of safe assets and hence alleviating the safe asset shortage. Instead, they simultaneously increase the future value of risky assets and the risky interest rate, leaving the current value of risky assets unchanged. As a result, aggregate demand and output remain unchanged. In a safety trap, policy commitments that work support future bad states. This is a higher level of requirements than in the standard New-Keynesian liquidity-trap mechanism where any future wealth increase has the potential to stimulate the economy. Indeed, it is natural to question whether monetary authorities would have the ability to lower interest rates in future bad states, since they might coincide with yet another safety or liquidity trap.

We illustrate these points with an example of forward guidance policy that would work in a New-Keynesian liquidity trap environment but not in SAM. Since public debt is not key to our main concern here, we temporarily revert to the model of Section 2 where there are only private assets, and focus on the New Keynesian version with rigid prices.

We introduce two extensions to that model. First, we introduce the possibility of another independent Poisson shock, which raises output to $\gamma X>X$ and removes the possibility of the bad shock. It occurs with nonzero intensity $\lambda^{G}$. We refer to this shock as the good shock, in contrast to the bad Poisson shock that concerns Knightians in our main analysis. Second, we allow agents to produce $\zeta>1$ units of output per unit of input. However, we imagine that there is a large utility loss from doing so.

This model works like that in Section 2. It features the possibility of a safety trap, indeed $\xi$ is determined by the exact same equation. The only difference is in the (risky) interest rate $r$. The interest rate $r$ is now determined by the following set of equations (and $\lambda^{G}$ only 
enters the last of these equations):

$$
\begin{gathered}
V^{r}=(\xi-\rho \mu) \frac{X}{\theta}, \\
V^{\mu}=\rho \mu \frac{X}{\theta}, \\
\underline{r}^{K} V^{\mu}=\delta^{\mu} X, \\
r V^{r}=\xi \delta X-\delta^{\mu} X+\lambda^{G}(\gamma-\xi) \frac{X}{\theta} .
\end{gathered}
$$

This yields

$$
r=\frac{\xi \delta \theta-\underline{r}^{K} \rho \mu+\lambda^{G}(\gamma-\xi)}{\xi-\rho \mu}
$$

In New-Keynesian models of the liquidity trap (see e.g. Krugman 1998, Eggertsson and Woodford 2003, and Werning 2012), committing to keep the interest rate low in the future once the economy recovers (after the good Poisson shock) stimulates the economy - a policy often referred to as forward guidance. The latter works by creating a boom in the future, which raises current demand through a combination of a wealth effect (higher income in the future) and substitution effect (lower real interest rates because of inflation). Our model shuts down the latter mechanism, and the former is ineffective since what matters is the perceived wealth of Knightians, not that of Neutrals.

In our model a commitment to low interest rates after the good Poisson shock only increases the value of risky assets. Consider the following policy: Suppose that the good Poisson shock occurs at $\tau$. After the good Poisson shock, the central bank stimulates the economy by setting the interest rate $i_{t}$ below the natural interest rate $\delta \theta$ until $\tau+T$, at which point it reverts to setting the nominal interest rate equal to the natural interest rate $i=\delta \theta$. For $t>\tau+T$, output is equal to potential so that $\zeta_{t}=1$. For $\tau \leq t \leq t+T$, output is above potential, and capacity utilization satisfies a simple differential equation

$$
\frac{\dot{\zeta}_{t}}{\zeta_{t}}=i_{t}-\delta \theta \leq 0,
$$

with terminal condition

$$
\zeta_{\tau+T}=1
$$

The solution is

$$
\zeta_{t}=e^{\int_{t}^{\tau+T}\left(\delta \theta-i_{s}\right) d s}
$$


By lowering interest rates, the central bank creates a temporary boom after the Poisson shock. This boom boosts the value of risky assets immediately after the good Poisson shock from

$$
\gamma \frac{X}{\theta}
$$

to

$$
\gamma \zeta_{\tau} \frac{X}{\theta}>\gamma \frac{X}{\theta}
$$

Let us now work backwards to understand the effects of this policy before the good Poisson shock, while the economy is in a safety trap. The only effect of this policy is to increase the interest rate $r$ during the safety trap to

$$
r=\frac{\xi \delta \theta-\underline{r}^{K} \rho \mu+\lambda^{G}\left(\gamma \zeta_{\tau}-\xi\right)}{\xi-\rho \mu} .
$$

This increase in the interest rate is such that the value of risky assets (and hence the wealth of Neutrals) is unchanged, despite the fact that their value after a good Poisson shock has increased. Importantly, the increase in $r$ is orthogonal to the safe-asset shortage problem. Since the policy leaves the supply of safe assets unchanged, it does not expand output, which remains depressed by exactly the same factor $\xi$.

There is one caveat to this conclusion. We have assumed that prices are entirely rigid. If prices could adjust gradually over time, then forward guidance could regain some kick: A commitment to lower interest rates after the good Poisson shock could increase inflation while the economy is in a safety trap. Under the interpretation of the model where the lower bound $\underline{r}^{K}$ arises because of the possibility of arbitrage between money and bonds (the zero lower bound), this would lower the safe interest rate $r^{K}$ and mitigate the recession. However, under the interpretation that the lower bound $\underline{r}^{K}$ arises from the inability of Knightians to survive lower real interest rates (or only at a high utility cost), then our negative conclusion on the effects of standard forward guidance policy remains. ${ }^{19}$

SAM is addressed more directly by committing to provide support during bad rather than good times, as we now explain. ${ }^{20}$ What would work in a safety trap would be a commitment to lower interest $i_{t}$ rates after the bad Poisson shock. By setting the nominal interest rate $i_{t}$

\footnotetext{
${ }^{19}$ The same comments apply to the unconventional tax policies considered by Correia, Farhi, Nicolini and Teles (2012), which here could simply take the form of an increasing path of sales taxes - say through a sales tax holiday - which would create inflation in consumer prices and hence reduce $r^{K}$.

${ }^{20}$ The OMT (outright monetary transactions) program established by the ECB in late 2012 is one such policy, and it had an immediate impact on the Eurozone risk perception.
} 
below the natural interest rate $\delta \theta$ after the bad Poisson shock, monetary authorities stimulate the economy and inflate the value of safe assets to

$$
\hat{V}^{\mu}=\rho \mu \frac{\zeta_{\tau}}{\theta} X
$$

where

$$
\zeta_{\tau}=e^{\int_{\tau}^{\tau+T}\left(\delta \theta-i_{s}\right) d s}
$$

This mitigates the recession in the safety trap by raising $\xi$ to $\xi \zeta_{\tau}>\xi$ (the analysis is almost identical to that of a monetary stimulus after the good Poisson shock explained above). ${ }^{21,22}$

However it is natural to question whether monetary authorities would have the ability to lower interest rates in that state. If indeed the bad state happens to coincide with yet another safety or liquidity trap, monetary authorities could find themselves unable to deliver a lower interest rate. Perhaps a more realistic policy option would be a commitment by the authorities to buy up safe assets at an inflated price after the Poisson shocks - a form of government (central bank?) put. A commitment to buy up safe private assets at an inflated value $\sigma \rho \mu \frac{X}{\theta}>\rho \mu \frac{X}{\theta}$ would mitigate the recession and increase the value of $\xi$ to $\hat{\xi}$ where

$$
\hat{\xi}=\sigma \xi>\xi
$$

It could be carried out by monetary authorities but it does require spare fiscal capacity (in the form of taxes or seigniorage). ${ }^{23}$ This kind of public insurance policy has a crucial role to play in SAM. ${ }^{24}$

\footnotetext{
${ }^{21}$ Note we could just as well have used the model with public debt. The central banker's put works by increasing both the public and private sectors' ability to provide safe assets.

${ }^{22}$ Just like in New Keynesian models of the liquidity trap, and to the extent that they are possible at all, these forms of policy commitments raise time-consistency issues: Their efficacy hinges on the ability of monetary authorities to carry out credible commitments.

${ }^{23}$ Using the model of Section 3.1.3,we could also interpret $(1-\psi)$ as a government put. The lower is $\psi$, the higher is the government's commitment to support Knightian's portfolio should the Poisson event take place.

${ }^{24}$ See, e.g., Caballero and Kurlat (2010) for a proposal to increase the resilience of the financial system in a SAM environment. Also, see Brunnermeir et al (2012) for a related proposal in the context of the current Euro crisis.
} 


\section{Safety Traps versus Liquidity Traps}

The SAM environment and its safety trap shares many features in common with the Keynesian liquidity trap, however there are also important differences between them. In this section we highlight some of these differences by comparing the impact of several macroeconomic policies in these environments.

We consider the following simple model of a liquidity trap. It is a version of our model where the economy is in the unconstrained regime so that $r=r^{K}$ (which means the distinction between risky and riskless assets is irrelevant). We add one ingredient: the possibility of the bad shock is $\lambda>0$ rather than $\lambda=0$. This is necessary for interest rates $r$ to reach zero. Interest rates $r$ cannot go below zero because of the zero lower bound on nominal interest rates.

As long as the zero bound is not binding we have

$$
r=\delta \theta-\lambda(1-\mu)>0
$$

When the zero bound $r=0$ binds, the economy enters a recession $(\xi<1)$ where $\xi$ is determined by the requirement that $r=0$ :

$$
0=\delta \theta-\lambda\left(1-\frac{\mu}{\xi}\right),
$$

i.e.

$$
\xi=\frac{\mu}{1-\frac{\delta \theta}{\lambda}}
$$

The recession originates from a scarcity of assets (stores of value). It is more severe, the worse is the expected bad shock (the lower is $\mu$ ), the more likely is the bad shock (the higher $\lambda$ ), the higher the propensity to save (the lower $\theta$ ), and the lower is the ability of the economy to create assets that capitalize future income (the lower is $\delta$ ).

We can use this model to examine the effects of the same policies that we have considered in the context of the safety trap: balance sheet policies (QE and OT), fiscal policy (redistribution and government spending), and monetary policy commitments (forward guidance). 


\subsection{Balance Sheet Policies and Fiscal Policy}

\subsubsection{Public Debt, QE and OT}

We start with public debt, QE and OT. We introduce public debt in the model exactly as in Sections 3.1.2 and 3.1.3. The key point is that public debt issuances, QE and OT have no effect at all on the recession $\xi$ in the liquidity trap model. This precise irrelevance result relies on our assumption that dividends are taxed while the endowment of newborns (wages) is not. As a result, public debt issuances, QE and OT simply reshuffle the fraction of dividends that accrues to private asset holders and the fraction of dividends that is absorbed by taxes to pay interest on debt of various maturities. This assumption essentially renders our framework Ricardian, despite the fact that we have overlapping generations of agents. ${ }^{25}$ These conclusions about the irrelevance of $\mathrm{QE}$ and $\mathrm{OT}$ in liquidity traps must be contrasted with those reached in Sections 3.1.2 and 3.1.3 in safety traps. The effects of QE and OT in safety traps rely entirely on the (assumed) superior ability of the government to address a form of market incompleteness - the difficulty to isolate safe from risky assets.

\subsubsection{Redistributive Policies}

As long as the economy remains in the unconstrained regime, redistributing income or wealth away from Knightians towards Neutrals has no effect on the level of economic activity. Indeed, the relative wealth of Knigthian and Neutrals is irrelevant. As a result, and in contrast with the case of a safety trap, redistributive policies of the kind considered in Section 3.2.1 are powerless at simulating output in a liquidity trap.

There are versions of liquidity trap models where, like in our model, redistributive policies have stimulative effects (see e.g. Guerrieri and Lorenzoni 2011, Eggertsson and Krugman 2012). However, the relevant dimension of redistribution is different: The key is redistribution from high propensity to save agents to low propensity to save agents. By contrast, in our model, the key is redistribution from agents with high propensities to save with safe assets to agents with low propensities to save with safe assets.

\footnotetext{
${ }^{25}$ If we allowed the endowments of newborns to be taxed, then public debt issuances, QE and OT could have some non-Ricardian effects, depending on exactly how these taxes are levied, and hence affect economic activity in a liquidity trap.
} 


\subsubsection{Fiscal Stimulus}

Finally, we consider the effects of fiscal stimulus (government spending paid for by taxes on dividends) in a liquidity trap as in Section 3.2.2. The value of assets must be

$$
\theta(V+D)=(1-G) \xi X
$$

which can be combined with the asset pricing equation to yield

$$
r(V+D)=(\delta-G) \xi X-\lambda\left(\xi(1-G)-\mu\left(1-G^{\mu}\right)\right) \frac{X}{\theta}
$$

implying that the interest rate is

$$
r=\frac{(\delta-G) \xi \theta-\lambda\left(\xi(1-G)-\mu\left(1-G^{\mu}\right)\right)}{(1-G) \xi}
$$

If the zero bound is binding so that $r=0$ and $\xi<1$, we have

$$
\xi=\frac{\mu\left(1-G^{\mu}\right)}{1-\frac{\delta \theta}{\lambda}-G\left(1-\frac{\theta}{\lambda}\right)} .
$$

As long as $\frac{\theta}{\lambda}<1$, an increase in $G$ increases $\xi$ (output). This can be understood through the effects of this policy on the natural interest rate (in the flexible price economy). On the one hand, an increase in $G$ reduces private wealth and asset values, and hence moderates the drop in asset values that occurs if the bad shock occurs. This increases the natural interest rate. On the other hand, an increase in $G$ is financed by taxes on dividends, which reduces the natural interest rate. The parameter $\frac{\theta}{\lambda}$ indexes the relative strength of the second effect vs. the first effect. When $\frac{\theta}{\lambda}<1$, the first effect dominates. Because the interest rate is stuck at zero, the increase in $G$ reduces the gap between the actual and natural interest rates and mitigates the recession. ${ }^{26}$

The important point for us here is that the potential expansionary effect of short-term fiscal stimulus (financed by taxes on capital income) is in contrast with our safety trap result in Section 3.2.2, where we found that such policy was powerless at stimulating output once

\footnotetext{
${ }^{26}$ Once again, one channel (the inflation channel) through which government spending stimulates output in traditional New Keynesian models of the liquidity trap is absent in our model. Fiscal multipliers are large at the zero lower bound because government spending creates inflation and hence lowers real interest rates.
} 
the government is unable to produce additional safe assets. ${ }^{27}$

Conversely, just as in Section 3.2.2, long-run fiscal consolidation (a reduction in $G^{\mu}$ ) also stimulates output. The long-term reduction in government spending increases asset values and increases private current spending through a wealth effect. It works to reduce the asset shortage that is at the root of the liquidity trap.

\subsection{Forward Guidance}

We now turn to monetary policy commitments. To do so, we introduce the possibility of a good shock as in Section 4. The Poisson shock now has intensity $\hat{\lambda}$. When the Poisson shock hits, output increases to $\gamma X$ with $\gamma>1$ with probability $\lambda^{G}=\pi \hat{\lambda}$, and decreases to $\mu X$ with $\mu<1$ with probability $\lambda=(1-\pi) \hat{\lambda}$. In a liquidity trap $r=0$, the recession is now determined by

$$
0=\delta \theta-\lambda\left(1-\frac{\mu}{\xi}\right)-\lambda^{G}\left(1-\frac{\gamma}{\xi}\right)
$$

i.e.

$$
\xi=\frac{\frac{\lambda}{\lambda+\lambda^{G}} \mu+\frac{\lambda^{G}}{\lambda+\lambda^{G}} \gamma}{1-\frac{\delta \theta}{\lambda+\lambda^{G}}} .
$$

Consider the following policy: Suppose that the good Poisson shock occurs at $\tau$. After the good Poisson shock, the central bank stimulates the economy by setting the interest rate $i_{t}$ below the natural interest rate $\delta \theta$ until $\tau+T$, at which point it reverts to setting the nominal interest rate equal to the natural interest rate $i=\delta \theta$. For $t>\tau+T$, output is equal to potential so that $\zeta_{t}=1$. For $\tau \leq t \leq t+T$, output is above potential, and capacity utilization satisfies a simple differential equation

$$
\frac{\dot{\zeta}_{t}}{\zeta_{t}}=i_{t}-\delta \theta \leq 0
$$

with terminal condition

$$
\zeta_{\tau+T}=1
$$

The solution is

$$
\zeta_{t}=e^{\int_{t}^{\tau+T}\left(\delta \theta-i_{s}\right) d s}
$$

\footnotetext{
${ }^{27}$ Because the environment is not Ricardian, it matters whether government spending is financed through taxes or capital or labor income. Just like in safety traps, with taxes on labor income, short-run fiscal stimulus is more effective. This is because the associated tax increase works to reduce the demand for assets (labor income taxes) instead of decreasing the supply of assets (capital income taxes).
} 
By lowering interest rates, the central bank creates a temporary boom after the good Poisson shock. This boom boosts the value of risky assets immediately after the good Poisson shock from

$$
\gamma \frac{X}{\theta}
$$

to

$$
\gamma \zeta_{\tau} \frac{X}{\theta}>\gamma \frac{X}{\theta}
$$

This policy alleviates the recession while the economy is in a liquidity trap, pushing $\xi$ to $\hat{\xi}$ where

$$
\hat{\xi}=\xi \frac{\frac{\lambda}{\lambda+\lambda^{G}} \mu+\frac{\lambda^{G}}{\lambda+\lambda^{G}} \zeta_{\tau} \gamma}{\frac{\lambda}{\lambda+\lambda^{G}} \mu+\frac{\lambda^{G}}{\lambda+\lambda^{G}} \gamma}>\xi
$$

Basically, committing to low interest rates after the good Poisson shock increases the value of assets while the economy is in the liquidity trap. This wealth effect increases demand and mitigates the recession. Forward guidance works by alleviating the asset shortage that is at the root of the recession. ${ }^{28}$

Forward guidance trades off a future boom against a mitigation of the current recession and hence raises time-consistency issues. Because of the utility loss that comes with the boom, monetary authorities might be tempted to renege on their commitment to keep interest rates low when time comes to deliver on this promise. Nevertheless, our main point here is that the effectiveness of forward guidance in liquidity traps is to be contrasted with its relative ineffectiveness in safety traps.

\section{Final Remarks}

Our model illustrates the essence of SAM and its implications for standard macroeconomic policy tools, but it leaves untouched critical considerations for the dynamics of the world economy in the medium term.

Given the faster growth of safe-asset-consumer economies than that of safe-asset-producer economies, absent major financial innovations, SAM is only likely to get worse over time. Aside from temporary cyclical recoveries in spreads and output, it is our conjecture that SAM

\footnotetext{
${ }^{28}$ We should emphasize that one channel through which forward guidance works in traditional New Keynesian models of the liquidity trap - reducing real interest rates by creating inflation-is absent from this model because we have assumed that prices are rigid. Instead, forward guidance works entirely through a wealth effect by boosting asset values, wealth, and hence spending.
} 
will remain as a structural drag, lowering safe rates, increasing safety spreads, straining the financial system, and weakening the effectiveness of conventional monetary policy.

There is significant incentive to produce major financial innovations to address the safety gap, which can be a source of concern in itself, as the financial system capacity to extract safe tranches from risky assets is likely to get stretched along lines similar to those behind the subprime crisis. However, it is important to recognize that this is a chronic structural and macroeconomic problem that does not get remedied, but only reallocated, with standard regulatory pressure (which may have merits on its own). Instead, what is needed is publicprivate cooperation in increasing the efficiency of production of safe assets, as well as policies that reduce the demand for such assets.

What are these policies? What are the political limits on pre-paid "bailout" agreements and cross-country insurance arrangements that may be needed to reduce the SAM problem? What are the intergenerational transfers that SAM requires and, are these acceptable, especially for current retirees? Will SAM lead to widespread "gambling for resurrection" type mechanisms from those institutions and corporations whose implicit liabilities are inconsistent with depressed safe rates of return? How much of the adjustment will take place on the supply side of the economy via reduced entrepreneurial risk taking? We are just beginning to comprehend the implications of SAM for macroeconomic policy and politics, but it is already apparent that these are broad and significant. 


\section{References}

[1] Acharya, Viral V. and Philipp Schnabl. 2009. "Do Global Banks Spread Global Imbalances? The Case of Asset-Backed Commercial Paper During the Financial Crisis of 2007-09," Paper presented at the 10th Jacques Polak Annual Research Conference, International Monetary Fund. November.

[2] Bansal, Ravi and John W. Coleman, 1996, "A Monetary Explanation of the Equity Premium, Term Premium, and Risk-Free Rate Puzzles," Journal of Political Economy, University of Chicago Press, vol. 104(6), pp. 1135-71, December.

[3] Barro, Robert .J and Herschel I. Grossman, 1971, "A General Disequilibrium Model of Income and Employment," American Economic Review, 61(1), pp. 82-93, March.

[4] Bénassy, Jean-Pascal, 1986, "Macroeconomics: An Introduction to the Non-Walrasian Approach," Academic Press, Orlando.

[5] Bernanke, Ben, Carol Bertaut, Laurie Ponder DeMarco, and Steven Kamin, 2011. "International Capital Flows and the Returns to Safe Assets in the United States, 20032007," International Finance Discussion Paper 1014, Federal Reserve.

[6] Caballero, Ricardo J., 2006. "On the Macroeconomics of Asset Shortages." In The Role of Money: Money and Monetary Policy in the Twenty-First Century The Fourth European Central Banking Conference 9-10 November, Andreas Beyer and Lucrezia Reichlin, editors, pp. 272-283.

[7] Caballero, Ricardo J., 2009. "The 'Other' Imbalance and the Financial Crisis," Paolo Baffi Lecture, Bank of Italy.

[8] Caballero, Ricardo J., Emmanuel Farhi and Pierre-Olivier Gourinchas, 2008a, "Financial Crash, Commodity Prices, and Global Imbalances." Brookings Papers on Economic Activity, Fall, pp. 1-55.

[9] Caballero, Ricardo J., Emmanuel Farhi and Pierre-Olivier Gourinchas, 2008b, "An Equilibrium Model of "Global Imbalances" and Low Interest Rates." American Economic Review, 98(1), pp. 358-393.

[10] Caballero, Ricardo J. and Arvind Krishnamurthy, 2009, "Global Imbalances and Financial Fragility," American Economic Review, May. 
[11] Christiano, Lawrence, Martin Eichenbaum, and Sergio Rebelo, 2011, "When Is the Government Spending Multiplier Large?," Journal of Political Economy, 119(1), pp. 78-121.

[12] Correia, Isabel, Emmanuel Farhi, Juan-Pablo Nicolini and Pedro Teles, "Unconventional Fiscal Policy at the Zero Bound," forthcoming in the American Economic Review.

[13] Coval, Joshua D., Jakub W. Jurek and Erik Stafford. 2009, "The Economics of Structured Finance," Journal of Economic Perspectives, Vol. 23, No. 1, Winter.

[14] Eggertsson, Gauti B., and Paul Krugman, 2012, "Debt, Deleveraging, and the Liquidity Trap: A Fisher-Minsky-Koo Approach," Quarterly Journal of Economics, 127(3), pp. 1469-1513.

[15] Eggertsson, Gauti B., and Michael Woodford, 2003, "The Zero Bound on Interest Rates and Optimal Monetary Policy," Brookings Papers on Economic Activity, pp. 139-211.

[16] Farhi, Emmanuel, Pierre-Olivier Gourinchas, and Helene Rey, "Reforming the International Monetary System," CEPR ereport, Setpember 2011.

[17] Farhi, Emmanuel, and Ivan Werning, 2012, "Fiscal Multipliers: Liquidity Traps and Currency Unions," NBER working paper 18381.

[18] Gennaioli, Nicola, Andrei Shleifer, and Robert Vishny, 2011. "Neglected Risks, Financial Innovation, and Financial Fragility," forthcoming in the Journal of Financial Economics.

[19] Gorton, Gary B., 2010, "Slapped by the Invisible Hand: The Panic of 2007," Oxford University Press.

[20] Gorton, Gary B. and Andrew Metrick, 2012, "Securitized Banking and the Run on Repo," Journal of Financial Economics 104, 425-451.

[21] Gorton, Gary B. and Andrew Metrick, 2010, "Haircuts," Federal Reserve Bank of St. Louis, Review 92(6).

[22] Gorton, Gary B. and Guillermo Ordoñez, 2013, "The Supply and Demand for Safe Assets," NBER working paper 18732.

[23] Gorton, Gary B., and Nicholas Souleles. 2006. "Special Purpose Vehicles and Securitization," in The Risks of Financial Institutions, edited by Rene Stulz and Mark Carey. University of Chicago Press. 
[24] Gourinchas, Pierre-Olivier and Hélène Rey. 2007. "From World Banker to World Venture Capitalist: US External Adjustment and The Exorbitant Privilege," in Richard Clarida, editor, G7 Current Account Imbalances: Sustainability and Adjustment, The University of Chicago Press, pp. 11-55.

[25] Greenwood, Robin, and Dimitri Vayanos, 2010, "Price Pressure in the Government Bond Market," American Economic Review, 100(2), pp. 585-90, May.

[26] Greenwood, Robin, Sam Hanson, and Jeremy Stein, 2012, "A Comparative-Advantage Approach to Government Debt Maturity", mimeo, Harvard.

[27] Guerrieri, Veronica, and Guido Lorenzoni, 2011, "Credit Crises, Precautionary Savings, and the Liquidity Trap," NBER working paper 17583.

[28] Gurkaynak, Refet S., Brian Sack, and Jonathan H. Wright, 2007, "The U.S. Treasury yield curve: 1961 to the present," Journal of Monetary Economics, Elsevier, 54(8), pp. 2291-2304, November.

[29] Hall, Robert E., 2011a, "The Long Slump," American Economic Review, 101, pp. 431469.

[30] Hall, Robert E., 2011b, "Clashing Theories of Unemployment," mimeo, Hoover Institution and Stanford University.

[31] Holmström, Bengt and Jean Tirole, 1998, "Private and Public Supply of Liquidity," Journal of Political Economy, 106(1), pp. 1-40.

[32] Keynes, John M, 1936, "The General Theory of Employment, Interest, and Money," Macmilan.

[33] Kocherlakota, Narayana, 2012, "Incomplete Labor Markets," mimeo, Federal Reserve Bank of Minneapolis.

[34] Korinek, Anton and Alp Simsek, 2013, "Liquidity Traps and Excessive Leverage", mimeo, MIT.

[35] Krishnamurthy, Arvind and Annette Vissing-Jorgensen, 2011, "The Effects of Quantitative Easing on Interest Rates: Channels and Implications for Policy," Brookings Papers on Economic Activity. 
[36] Krishnamurthy, Arvind and Annette Vissing-Jorgensen, 2012, "The Aggregate Demand for Treasury Debt," Journal of Political Economy, 120:2, pp. 233-267

[37] Krugman, Paul R., 1998, "It's Baaack: Japan's Slump and the Return of the Liquidity Trap," Brookings Papers on Economic Activity, 29(2), pp. 137-206.

[38] Malinvaud, Edmond. 1977, "Theory of Unemployment Reconsidered," Oxford: Blackwell Publishers.

[39] Obstfeld, Maury, 2011, "International Liquidity: The Fiscal Dimension," Monetary and Economic Studies, pp. 33-48, November.

[40] Stein, Jeremy C., 2012, "Monetary Policy as Financial-Stability Regulation," Quarterly Journal of Economics, 127(1), pp. 57-95.

[41] Werning, Ivan, 2012, "Managing a Liquidity Trap: Monetary and Fiscal Policy," MIT mimeo.

[42] Woodford, Michael, 1990, "Public Debt as Private Liquidity," American Economic Review, Papers and Proceedings 80, pp. 382-88, May.

[43] Woodford, Michael, 2003, "Interest and Prices," Princeton University Press. 


\section{Appendix}

\subsection{Extensions}

\subsubsection{Extension of the Model with Pooling}

Assume that agents cannot by themselves diversify their portfolios. Otherwise the issue of pooling becomes irrelevant. The reason could be that they do not have the expertise to do this. Alternatively, there could be some indivisibilities in assets (in other words vertical - as opposed to horizontal - tranching is not perfect, vertical tranches cannot be too thin), that could arise from a desire to minimize structuration/issuance/transaction costs.

To introduce a role for pooling, we imagine that trees have idiosyncratic risk. The dividend of each tree follows the process: On top of the macro Poisson shock, there is a sectoral shock $\varepsilon$ that hits the dividend of the tree if the macro Poisson shock occurs. Hence the dividend is 1 if there is no Poisson shock and $\varepsilon \mu$ if a Poisson shock has occurred, where $\varepsilon$ is idiosyncratic to a sector. The shock $\varepsilon$ has mean 1 and the lower bound of its support is $\underline{\varepsilon}<1$. There is a continuum of sectors. Assets from different sectors can be pooled. The financial sector has the ability to pool assets from a mass $\gamma$ of different sectors. The rest $1-\gamma$ of the sectors cannot be pooled. Only a fraction $\hat{\rho}$ of the assets that can be pooled can be tranched, and only a fraction $\tilde{\rho}$ of the assets that cannot be pooled can be tranched. The model is then isomorphic to the model with an imperfect ability to tranch with $\rho=\hat{\rho} \gamma+\tilde{\rho}(1-\gamma) \underline{\varepsilon}$.

\subsubsection{Flight to Safety and Output Loss}

Up to now we have assumed production is exogenous and focused on the spread side of SAM. But in reality production and demand decisions are also strongly influenced by risk perceptions and the corresponding spreads. In this section we focus on a supply side mechanism, while in the main text, we focus on demand.

Corporations undertake a host of risk-reducing measures, such as cash preservation and productive investment postponement, despite the impact of these measures on expected revenue. ${ }^{29}$ We capture this flight to safety aspect of SAM by adding a simple tradeoff between risk and return in production. We assume that tranching a tree into a safe part

\footnotetext{
${ }^{29}$ During risk-off episodes, corporations often try to replicate bond-like payouts from their equity by implementing equity buy-back policies and predictable dividend distribution streams.
} 
and a risky part consumes resources (which in reality could be thought of as the resources consumed by a sophisticated financial system). In particular, a tranchable tree generates a lower dividend $\hat{\delta}<\delta .^{30}$ Of course the advantage of tranching is that the safe part can be sold at a high price.

We denote by $\tilde{\rho} \in(0,1)$ the fraction of trees that are tranched in equilibrium. It is easier to change variables and define

$$
\rho \equiv \frac{\tilde{\rho} \frac{\hat{\delta}}{\delta}}{1-\tilde{\rho}\left(1-\frac{\hat{\delta}}{\delta}\right)} .
$$

We exploit the monotonic (increasing) mapping between $\rho$ and $\tilde{\rho}$ and work directly with $\rho$, for the analysis becomes analogous to the baseline model with this endogenous value of $\rho$. We now turn to its determination.

In order for the equilibrium that we have characterized to be valid, it must be the case that the value of an untranched tree

$$
v^{n t}=\frac{1}{\theta} \frac{\delta}{1-\frac{(1-\alpha)(1-\delta)}{1-\rho \mu}}
$$

is the same as that of a tranched tree

$$
v^{t}=\frac{\mu}{\theta} \frac{\hat{\delta}}{\delta}\left[1+\frac{\frac{\alpha(1-\delta)}{\rho \mu}-\left(1-\frac{\delta}{\mu}\right)}{1-\frac{(1-\alpha)(1-\delta)}{1-\rho \mu}}\right] .
$$

A necessary and sufficient condition for this is

$$
\frac{\delta}{1-\delta}=\frac{\frac{\hat{\delta}}{\delta}}{1-\frac{\hat{\delta}}{\delta}} \frac{\alpha-\rho \mu}{\rho(1-\rho \mu)}
$$

The left-hand side of the equation is constant. The right-hand side of the equation is decreasing in $\rho$ with a value of $\infty$ at $\rho=0$ and of $\frac{\frac{\hat{\delta}}{\delta}}{1-\frac{\hat{\delta}}{\delta}} \frac{\alpha-\mu}{1-\mu}$ at $\rho=1$. The solution always features $\rho>0$, and satisfies $\rho<1$ as long as $\frac{\delta}{1-\delta}>\frac{\frac{\delta}{\delta}}{1-\frac{\delta}{\delta}} \frac{\alpha-\mu}{1-\mu} \cdot 31$

\footnotetext{
${ }^{30}$ For simplicity, we assume that the decision to pay the production cost does not change the fraction of the output of a tree which is capitalized. In other words, each tranched tree yields an output $\frac{\hat{\delta}}{\delta}$, a fraction $\delta$ of which is a capitalized dividend of $\hat{\delta}=\delta \frac{\hat{\delta}}{\delta}$.

${ }^{31}$ Note that we can have a corner solutions at $\rho=1$ where the value of an untranched tree is less than the value of a tranched tree.
} 
The solution $\rho$ is decreasing in $\mu$ and increasing in $\alpha$. The effect of $\mu$ directly impacts the attractiveness of tranching, independently of its effect on the safety premium. The effect of $\alpha$ is entirely driven by the safety premium: The higher $\alpha$, the higher the safety premium, the more agents fly to safety.

In summary, SAM affects production because in the absence of effective tranching mechanisms to satisfy demand for safe assets, production is distorted toward generating more safe assets and increase valuations. Safety rather than revenue maximization is what financial markets demand.

\subsubsection{Safe Asset Status and Self-Fulfilling Debt Crises}

Safe asset status is fragile. The safe asset status of a country's debt relies on the assurance that debt will be repaid should a Poisson shock occur. A country that has issued shortterm debt up to its fiscal capacity constraint might find itself subject to a self-fulfilling debt crisis. This situation can lead to doubts about the ability of the government to repay its debts after the Poisson shock. These doubts jeopardize the country's safe asset status immediately, which can force it into a partial default.

We assume that the country is a small open economy facing world interest rates $r$ and $r^{K}$ with $r>r^{K}$, and $r^{\mu}$, before and after the Poisson shock, respectively (the shock is assumed to be global). The country is up against its fiscal capacity constraint. Now imagine that when the Poisson shock hits, agents start questioning the ability of the government to repay its debt, triggering a self-fulfilling debt crisis exactly along the lines of Calvo (1988). More precisely, agents anticipate that a flow $\omega$ of debt will be repudiated per unit of time, and therefore require an interest rate $r^{\mu}+\omega$ on the government's debt. Moreover, we assume that a default generates extra fiscal cost $\alpha$ per unit of repudiated debt. ${ }^{32}$ The only level of debt which is consistent with these expectations is

$$
D=\frac{\delta \bar{\tau}^{\mu} \mu X}{r^{\mu}+\alpha \omega} .
$$

The higher $\omega$, the lower the level of debt. Note the importance of the assumption that the country is up against its fiscal capacity so that $\tau^{\mu}=\bar{\tau}^{\mu}$ cannot be increased. If instead we

\footnotetext{
${ }^{32}$ For example, these could be legal costs. Whether the corresponding resources are dissipated or appropriated by a class of agents (lawyers) is not important in this section.
} 
have

$$
D=\frac{\delta \tau^{\mu} \mu X}{r^{\mu}}<\frac{\delta \bar{\tau}^{\mu} \mu X}{r^{\mu}}
$$

then any $\omega$ such that

$$
\left(r^{\mu}+\omega\right) D \leq \delta \bar{\tau}^{\mu} \mu X
$$

i.e.

$$
\omega \leq \bar{\omega} \text { where } \bar{\omega}=\delta\left(\bar{\tau}^{\mu}-\tau^{\mu}\right) \mu X
$$

cannot be an equilibrium: The government has enough fiscal room to weather an (out of equilibrium) adverse expectation shift up to $\bar{\omega}$ by simply increasing taxes, where $\bar{\omega}$ is increasing in fiscal slack $\bar{\tau}^{\mu}-\tau^{\mu}$. In a sense, having fiscal slack restricts the possibility of self-fulfilling debt crises. As long as we are ready to impose some upper bound $\omega^{\max }$ on the adverse expectation shift $\omega$ that we consider, a country with enough fiscal slack so that $\bar{\omega}>\omega^{\max }$ will be completely immune to these crises.

We can now ask what happens before the Poisson shock, when expectations about the ability of the government to repay its debt should a Poisson shock occur suddenly shift. We start in a situation where agents anticipate $\omega=0$ with

$$
\bar{D}=\frac{\delta \bar{\tau}^{\mu} \mu X}{r^{\mu}}
$$

and taxes $\tau$ are

$$
\tau \delta X=r^{K} \bar{D}
$$

Expectations suddenly shift to a situation where $\omega>0$. Since $\bar{D}>\frac{\delta \bar{\tau}^{\mu} \mu X}{r^{\mu}+\alpha \omega}$, debt immediately loses its safe asset status and the government must now pay an interest rate $r$ on its debt. Indeed the government budget constraint becomes

$$
\dot{D}_{t}=r D_{t}-\tau_{t} \delta X
$$

with

$$
D_{0}=\bar{D}
$$

What happens next depends on the ability or willingness of the government to adjust taxes $\tau_{t}$. The dynamics we have characterized are valid as long as taxes $\tau_{t}$ cannot be raised fast enough so that $r D_{t}>\tau_{t} \delta X$ for some time, but can eventually be increased enough to stabilize debt. However it might be impossible for the country to raise enough taxes once it faces an interest rate of $r$ instead of $r^{K}$. For example, it could be that the country cannot raise more 
taxes than $\tau$ because it is against its fiscal capacity $\tau=\bar{\tau}$ even before the Poisson shock hits. In that case, an immediate partial default (haircut) must occur in order to restore fiscal balance.

Our model features multiple equilibria. Once agents start questioning the safe asset status of a country (in a way that is entirely self-fulfilling), interest rates on debt rise, triggering a gradual buildup in debt followed by a fiscal adjustment in the form of a tax increase or a partial default.

This analysis leads to a potential narrative for the recent fiscal experience of some europeriphery countries. These countries were forced by the various fiscal costs associated with the recession - loss in fiscal revenues, government stimulus and bank bailouts - against their fiscal capacity. This jeopardized their safe asset status. From safe asset producers, they suddenly became risky asset producers, facing higher interest rates. This amplification mechanism contributed to producing an unsustainable fiscal situation.

\subsection{Proofs}

\subsubsection{Proofs for Section 2.1}

The goods market clearing condition is

$$
W=\frac{X}{\theta}
$$

The financial market clearing condition is

$$
W=V
$$

If we are in the unconstrained regime, then we have $r_{t}=r_{t}^{K}$, and summing up the wealth evolution equations

$$
\begin{gathered}
\dot{W}_{t}^{K}=-\theta W_{t}^{K}+\alpha(1-\delta) X+r_{t}^{K} W_{t}^{K}, \\
\dot{W}_{t}^{N}=-\theta W_{t}^{N}+(1-\alpha)(1-\delta) X+r_{t} W_{t}^{N},
\end{gathered}
$$

we find

$$
r_{t}=\delta \theta
$$


If we are in the constrained regime, then

$$
W_{t}^{K}=V^{\mu}=\rho \mu \frac{X}{\theta},
$$

which can be combined with the wealth evolution equation for Knightians

$$
\dot{W}_{t}^{K}=-\theta W_{t}^{K}+\alpha(1-\delta) X+r_{t}^{K} W_{t}^{K},
$$

to get

$$
r_{t}^{K}=\delta \theta-(1-\delta) \theta\left(\frac{\alpha-\rho \mu}{\rho \mu}\right) .
$$

We can then use the asset pricing equation for safe assets

$$
r_{t}^{K} V^{\mu}=\delta_{t}^{\mu} X
$$

to get

$$
\delta_{t}^{\mu}=\delta \rho \mu-(\alpha-\rho \mu)(1-\delta) .
$$

Similarly we can use the fact that

$$
W_{t}^{N}=V-V^{\mu}=(1-\rho \mu) \frac{X}{\theta},
$$

combined with the wealth accumulation equation for Neutrals

$$
\dot{W}_{t}^{N}=-\theta W_{t}^{N}+(1-\alpha)(1-\delta) X+r_{t} W_{t}^{N},
$$

to get

$$
r_{t}=\delta \theta+(1-\delta) \theta \frac{\alpha-\rho \mu}{1-\rho \mu} .
$$

We can verify that we have $r>r^{K}$ if and only if $\alpha>\rho \mu$.

If this condition is verified, then the economy always converges to the constrained region in the long run. If it is violated, then the economy is always in the unconstrained regime and the wealth of Knightians and Neutrals converges to

$$
\begin{gathered}
W_{\infty}^{K}=\alpha \frac{X}{\theta}<\rho \mu \frac{X}{\theta}=V^{\mu}, \\
W_{\infty}^{N}=(1-\alpha) \frac{X}{\theta} .
\end{gathered}
$$




\subsubsection{Proofs for Section 3.2.2}

We have

$$
\begin{gathered}
r^{K} D=\tau^{d} \delta X \\
r V=\delta(1-\hat{\tau}) X \\
\dot{W}_{t}^{K}=-\theta W_{t}^{K}+\alpha(1-\delta) X+r^{K} W_{t}^{K}, \\
\dot{W}_{t}^{N}=-\theta W_{t}^{N}+(1-\alpha)(1-\delta) X+r W_{t}^{N}, \\
G X=\left(\hat{\tau}-\tau^{d}\right) \delta X, \\
D=\frac{\tau^{\mu} \delta-G^{\mu}}{\delta-G^{\mu}} \mu \frac{X\left(1-G^{\mu}\right)}{\theta}, \\
W_{t}^{K}=D \\
W_{t}^{N}=V .
\end{gathered}
$$

This implies

$$
\begin{gathered}
D+V=\frac{X(1-G)}{\theta}, \\
V=\frac{X(1-G)}{\theta}-\frac{\tau^{\mu} \delta-G^{\mu}}{\delta-G^{\mu}} \mu \frac{X\left(1-G^{\mu}\right)}{\theta}=\left(1-\frac{\tau^{\mu} \delta-G^{\mu}}{\delta-G^{\mu}} \mu\right) \frac{X(1-G)}{\theta}+\frac{\tau^{\mu} \delta-G^{\mu}}{\delta-G^{\mu}} \mu \frac{X\left(G^{\mu}-G\right)}{\theta}, \\
\left(\theta-r^{K}\right) D=\alpha(1-\delta) X, \\
(\theta-r) V=(1-\alpha)(1-\delta) X,
\end{gathered}
$$

and hence

$$
\begin{gathered}
r^{K}=\theta-\theta(1-\delta) \frac{\alpha}{\frac{\tau^{\mu} \delta-G^{\mu}}{\delta-G^{\mu}} \mu} \frac{1}{1-G^{\mu}} \\
r=\theta-\theta(1-\delta) \frac{1-\alpha}{1-\frac{\tau^{\mu} \delta-G^{\mu}}{\delta-G^{\mu}} \mu} \frac{1}{(1-G)+\frac{\frac{\tau^{\mu} \delta-G^{\mu}}{\delta-G^{\mu}} \mu}{1-\frac{\tau^{\mu} \delta-G^{\mu}}{\delta-G^{\mu}} \mu}\left(G^{\mu}-G\right)} .
\end{gathered}
$$

We are in the constrained regime if and only if

$$
\frac{\alpha}{1-\alpha} \frac{1-\frac{\tau^{\mu} \delta-G^{\mu}}{\delta-G^{\mu}} \mu}{\frac{\tau^{\mu} \delta-G^{\mu}}{\delta-G^{\mu}} \mu}>\frac{1-G^{\mu}}{(1-G)+\frac{\frac{\tau^{\mu} \delta-G^{\mu}}{\delta-G^{\mu}} \mu}{1-\frac{\tau^{\mu} \delta-G^{\mu}}{\delta-G^{\mu}} \mu}\left(G^{\mu}-G\right)}
$$


i.e.

$$
\frac{\alpha}{1-\alpha} \frac{1-\frac{\tau^{\mu} \delta-G^{\mu}}{\delta-G^{\mu}} \mu}{\frac{\tau^{\mu} \delta-G^{\mu}}{\delta-G^{\mu}} \mu}>\frac{1}{1+\frac{1}{1-\frac{\tau^{\mu} \delta-G^{\mu}}{\delta-G^{\mu}} \mu} \frac{G^{\mu}-G}{1-G^{\mu}}} .
$$

